OPEN ACCESS

Edited by:

Per Morten Sandset,

Oslo University Hospital

Rikshospitalet, Norway

Reviewed by:

Gemma Vilahur,

Cardiovascular Research Center

CSIC-ICCC, Spain

Alexandre Francois Roy Stewart,

University of Ottawa Heart Institute,

Canada

Gianmarco de Donato,

University of Siena, Italy

*Correspondence:

Christine Brostjan,

Medical University of Vienna,

Department of Surgery, Anna Spiegel

Center for Translational Research,

Vienna General Hospital AKH

25.05.002, Lazarettgasse 14,

A-1090 Vienna, Austria christine.brostjan@meduniwien.ac.at

Specialty section:

This article was submitted to Thrombosis, a section of the journal Frontiers in Cardiovascular Medicine

Received: 22 December 2014 Accepted: 10 April 2015

Published: 26 May 2015

Citation:

Piechota-Polanczyk A, Jozkowicz A Nowak W, Eilenberg W, Neumayer C,

Malinski T, Huk I and Brostjan C

(2015) The abdominal aortic

aneurysm and intraluminal thrombus: current concepts of development and treatment.

Front. Cardiovasc. Med. 2:19. doi: 10.3389/fCvm.2015.00019

\section{The abdominal aortic aneurysm and intraluminal thrombus: current concepts of development and treatment}

\author{
Aleksandra Piechota-Polanczyk ${ }^{1,2}$, Alicja Jozkowicz ${ }^{3}$, Witold Nowak ${ }^{3}$, Wolf Eilenberg ${ }^{1}$, \\ Christoph Neumayer ${ }^{1}$, Tadeusz Malinski ${ }^{4}$, Ihor Huk ${ }^{1}$ and Christine Brostjan ${ }^{1 *}$ \\ ${ }^{1}$ Department of Surgery, Medical University of Vienna, Vienna, Austria, ${ }^{2}$ Department of Biochemistry, Medical University of \\ Lodz, Lodz, Poland, ${ }^{3}$ Department of Medical Biotechnology, Jagiellonian University, Krakow, Poland, ${ }^{4}$ Department of \\ Chemistry and Biochemistry, Ohio University, Athens, OH, USA
}

The pathogenesis of the abdominal aortic aneurysm (AAA) shows several hallmarks of atherosclerotic and atherothrombotic disease, but comprises an additional, predominant feature of proteolysis resulting in the degradation and destabilization of the aortic wall. This review aims to summarize the current knowledge on AAA development, involving the accumulation of neutrophils in the intraluminal thrombus and their central role in creating an oxidative and proteolytic environment. Particular focus is placed on the controversial role of heme oxygenase 1/carbon monoxide and nitric oxide synthase/peroxynitrite, which may exert both protective and damaging effects in the development of the aneurysm. Treatment indications as well as surgical and pharmacological options for AAA therapy are discussed in light of recent reports.

Keywords: aortic aneurysm, abdominal, intraluminal thrombus in aortic aneurysms, neutrophils, heme oxygenase-1, nitric oxide synthase

\section{Epidemiology and Risk Factors}

"Aneurysm" is defined as dilatation of an artery being at least 1.5 times larger than its expected normal diameter (1). Thus, an abdominal aortic aneurysm (AAA) is given when the maximum diameter is $30 \mathrm{~mm}$ or more (2). Approximately, $80 \%$ of AAAs occur in the infrarenal aorta (3). In general, "atherosclerotic" aneurysms represent the vast majority of AAAs (Figure 1).

The prevalence of AAAs depends on patients' age, gender, and geographical location (4). Primarily, elder men are affected. Men's prevalence of AAAs below $50 \mathrm{~mm}$ in diameter increases from $1.3 \%$ below 45 years to $12.5 \%$ above 75 years (2). For women, the prevalence ranges from 0 to $5.2 \%$, respectively, but the risk of rupture is four times greater. The underlying mechanisms of sex differences are not fully understood, although women seem to be protected by female sex hormones (2). Smoking is another strong risk factor for the development of AAAs due to its promoting effects on inflammation, proteolysis, and smooth muscle cell (SMC) apoptosis (5). Enhanced aneurysm growth and an increased risk of rupture have been described (6). Other risk factors comprise previous vascular aneurysms, coronary artery and cerebrovascular disease, atherosclerosis, hyperlipidemia, and hypertension (4). An observational study recently demonstrated that a low vitamin $\mathrm{D}$ status was associated with the presence of larger AAAs in elder men (7). Moreover, various microorganisms have been associated with the pathogenesis of AAAs (8). 


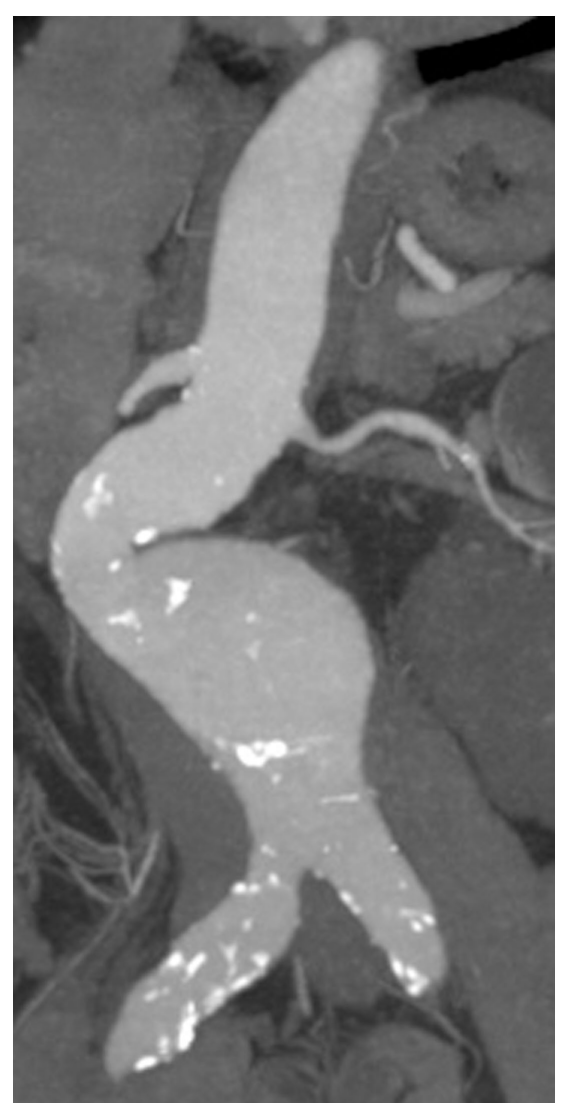

FIGURE 1 | CT recording of an infrarenal AAA with eccentric shape and sites of calcification (atherosclerotic plaques highlighted in white).

In addition to these environmental components, genetic aspects play an important role. A positive family history for AAA especially in male first-degree relatives is associated with an increased risk for AAA (9). Moreover, alterations on chromosome 9p21 are accompanied with a $20 \%$ increased risk of developing AAA (10). Other genetic approaches suggested that aberrations of lipid metabolism and proteolytic pathways are the key contributors to disease. Some of these associations (e.g., lipoprotein receptor-related protein-1) are not associated with atherosclerosis, indicating pathways unique to AAA (11). Distinct connective tissue disorders such as Marfan syndrome, Ehlers-Danlos syndrome, and Loeys-Dietz syndrome also go along with an increased risk for AAAs (12).

\section{The Intraluminal Thrombus}

In $70-80 \%$ of AAA patients, the vessel wall is covered by an intraluminal thrombus (ILT, Figure 2), which generally does not preclude blood flow and shows little compression throughout the cardiac cycle $(13,14)$. While mural thrombosis is frequently observed in aneurysmal disease, the complete vessel occlusion is a comparably rare event associated with a high rate of mortality (15).

An inhomogeneous thrombus structure was reported early on, with a stiffer luminal side composed of a dense fibrin network
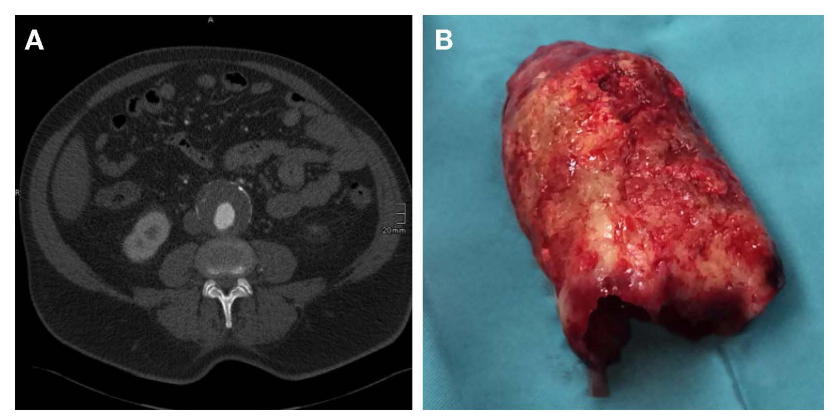

FIGURE 2 | (A) CT axial image of an infrarenal AAA with intraluminal thrombus. (B) Corresponding, massive, intraluminal thrombus removed during open surgical repair.

invaded by leukocytes and erythrocytes (16). By contrast, the medial and abluminal ILT layers were found to be largely devoid of cellular constituents and to exhibit progressive fibrinolysis and hence decreased thrombus strength and stiffness (17). Recent reports have indicated that ILT structure may indeed be more diverse than previously thought. When luminal, medial, and abluminal ILT layers were evaluated for mechanical properties, three subtypes of ILTs were identified (13). While the majority of investigated thrombi displayed a multi-layered morphology with gradually decreasing strength and stiffness from the distinct luminal to the thick medial/abluminal side (type 1), examples of multi-layered ILTs with an abrupt loss of mechanical resistance from luminal layers to rather thin and highly degraded medial/ abluminal layers were also observed (type 2). Of interest, a third type of single-layered ILT of almost fluid-like consistency was reported for a limited number of cases (13). Future studies will have to elucidate the pathogenesis and cellular/molecular composition of these distinct ILT variants. Importantly, based on the possibilities of medical imaging, the potential correlation of ILT subtype with disease progression and risk of rupture should be evaluated.

Macromolecular transport is promoted by centrifugal convection from the luminal to the abluminal side of the fibrin network and is further supported by the system of so-called "canaliculi" (17). Thus, molecules released and activated within the thrombus are readily transported to the vessel wall and affect aneurysm growth. Animal models have shown that limiting thrombus development with inhibitors of platelet activation strongly suppresses aneurysm formation (18). The effect is accompanied by a reduction in leukocyte infiltration and lower release of proteases within the mural thrombus, which results in decreased degradation of elastic fibers, and promotes thrombus colonization by SMCs. Thus, by sequestering and activating platelets, erythrocytes, neutrophils, and macrophages, the ILT exposes the vessel wall to a local milieu of highly concentrated cytokines, proteases, and reactive oxygen species (ROS) that promotes aneurysm development. In line, clinical studies report that ILT thickness correlates with AAA diameter, matrix metalloproteinase (MMP) levels, elastin degradation, and SMC apoptosis $(19,20)$. Furthermore, the presence of a large thrombus leads to localized hypoxia at the underlying aortic wall, 
which triggers adventitial angiogenesis and aggravates inflammatory infiltration from the outer vessel layers (21).

Despite this role in supporting the inflammatory and proteolytic mechanisms of AAA pathogenesis, the mural thrombus has repeatedly been suggested to protect the aneurysm from rupture by reducing the peak wall stress and altering wall stress distribution (22). However, this protective role seems to depend on the degree of thrombus attachment to the vessel wall (23). When bearing in mind that large thrombi are reportedly associated with faster AAA growth, the proteolytic weakening of the AAA wall may be the more predominant ILT effect when compared to wall stress relief (24).

Proteomics analysis of proteins sequestered by the ILT fibrin network revealed the expected prevalence of platelet-derived proteins such as clusterin and thrombospondin-1 (25), which are likely to be subjected to proteolytic processing within the local thrombus milieu thereby altering or activating protein function (26). Furthermore, as the ILT constitutes a site of continuous hemostasis and fibrin destruction, the respective coagulation and fibrinolysis factors are detected in thrombus tissue and elevated in AAA patients' blood (27). Fibrinogen, D-dimer (a cross-linked fibrin degradation product) and TAT (thrombin-antithrombin complex) prevailed in meta-analysis as diagnostic markers (28). Furthermore, circulating concentrations of hemostatic and fibrinolytic markers correlated with AAA and ILT size (29) and D-dimer blood levels were suited to predict the AAA growth rate (30). Importantly, large, population-based health screenings identified elevated blood levels of fibrinogen and tissue plasminogen activator to be associated with the occurrence of AAA within the subsequent $10-20$ years follow-up period. The fact that these plasma proteins were elevated years before the clinical manifestation of disease further supports the notion that deregulated hemostasis/ fibrinolysis is intricately involved in AAA pathogenesis - starting at an early stage of disease (31).

The factors potentially protecting or predisposing an individual to AAA development have been subjected to intense investigation. Loss of endothelial homeostasis resulting in pro-inflammatory and pro-coagulant activation is proposed to trigger the onset of disease. Two molecules that are central in regulating endothelial homeostasis and may thus exert a protective function are carbon monoxide (CO) and nitric oxide (NO) $(32,33)$. However, a more complex picture has emerged with $\mathrm{CO}, \mathrm{NO}$, and their enzymatic or reactive by-products exhibiting additional effects on, e.g., SMC proliferation and survival, which may promote rather than inhibit AAA development $(34,35)$. The loss of SMCs is a hallmark of the weakening vessel wall. In addition, AAA pathogenesis involves the destruction of elastic fibers and other matrix components, which seems to be vitally regulated by the accumulation of neutrophils in the growing ILT (36). These central mechanisms of disease development are highlighted in the following review sections.

\section{Role of Heme Oxygenase 1 in AAA and ILT}

Heme oxygenase-1 (Hmox1) and products of its activity can affect blood coagulation and formation of the thrombus. Hmox1 is an enzyme degrading heme - as released by erythrocyte trapping and hemagglutination in the thrombus - to carbon monoxide $(\mathrm{CO})$, ferrous iron $\left(\mathrm{Fe}^{2+}\right)$, and biliverdin, which is subsequently reduced by biliverdin reductase to bilirubin. Hmox1 has anti-oxidant, antiinflammatory, and cytoprotective activity that is crucial for blood vessel homeostasis (32) (Figure 3). Carbon monoxide activates guanylate cyclase, increases the level of cGMP (cyclic guanosine monophosphate), and subsequently inhibits platelet aggregation (37). Moreover, CO has been shown to suppress plasminogen activator inhibitor-1 (PAI-1) in a lung ischemia-driven thrombosis model (38) and subsequently affects fibrinolysis. Accordingly, both $\mathrm{CO}$ and bilirubin suppress PAI-1 in Hmox1-deficient mouse embryonic cells (39).

The majority of studies characterizing the role of Hmoxl in hemostasis and thrombosis have been performed on the occlusive types of thrombosis as opposed to AAA. Lack of heme oxygenase-1 in $H m o x 1^{-1-}$ mice leads to the faster occurrence of an occlusive thrombus in the carotid artery after photochemical injury (40). Basal levels of carotid tissue factor, platelet counts, bleeding time, and prothrombin time were not different in $H$ mox $1^{+/+}$and $H m o x 1^{-/-}$mice. However, vascular injury induced higher levels of arterial tissue factor and von Willebrand factor in $H m o x 1^{-1-}$ than in $H \operatorname{mox} 1^{+/+}$mice. Also, photochemical injury led to the endothelial damage only in $H \operatorname{mox} 1^{-/-}$mice. Finally, Hmox $1^{+/+}$mice transplanted with $H$ mox $1^{-/-}$bone marrow showed accelerated thrombosis in comparison to the Hmox $1^{+/+}$mice that received Hmox $1^{+/+}$bone marrow. Interestingly, faster occlusive thrombus formation in $\mathrm{Hmox}^{-1-}$ mice could be rescued with biliverdin, or when mice were inhaled with sublethal doses of CO (40).

Similarly, in the model of stasis-induced thrombosis in the inferior vena cava (IVC), the clot was bigger in $H_{m o x} 1^{-/-}$mice (41). IVC ligation increased Hmoxl transcription and protein levels in wild type endothelial and SMCs as well as in infiltrating

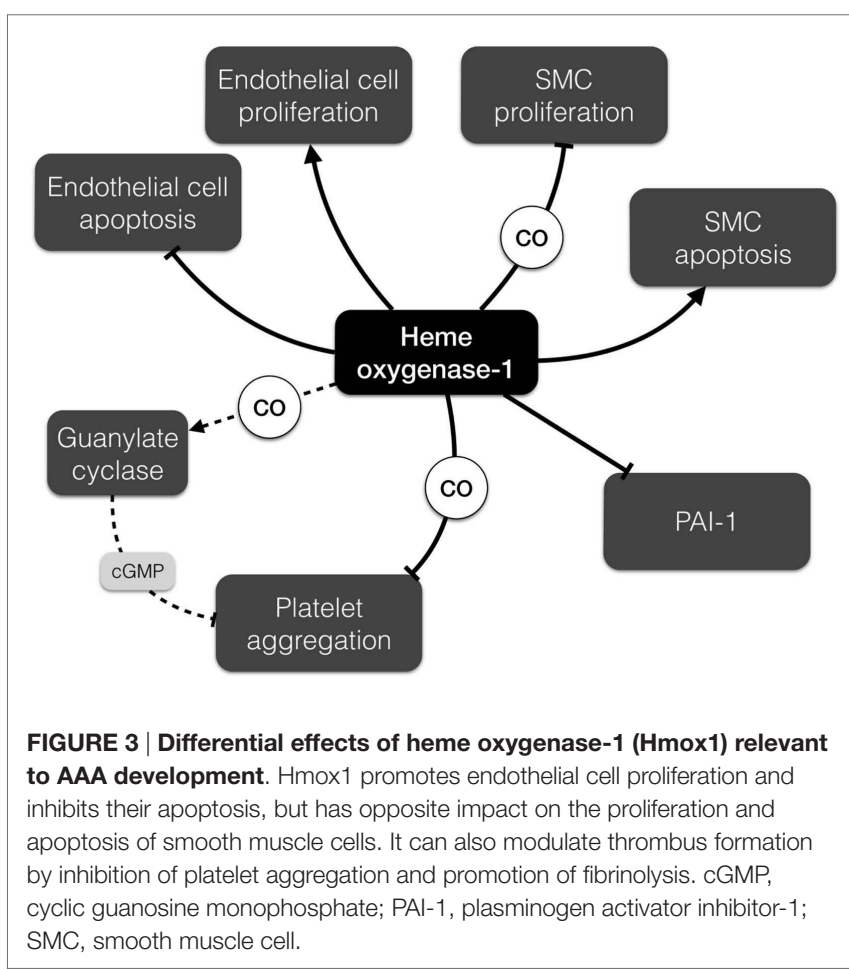


cells. It was demonstrated that IVC ligation in $\operatorname{Hmox}^{-/-}$mice induced a higher activation of nuclear factor kappa B (NF-кB) transcription factor and increased the inflammatory response as reflected by the expression of interleukin-6 (IL-6), monocyte chemoattracting protein-1 (MCP-1), stromal cell-derived factor-1, and $\mathrm{KC}$ (the murine homolog of interleukin-8) than in wild type animals. Importantly, the activity and expression of MMP-9 were also elevated in $H m o x 1^{-1-}$ mice. Finally, similar to the model of carotid artery injury in the work by True et al. (40), the vena cava ligation led to the increased production of tissue factor in Hmox $1^{-1-}$ mice (41).

Cobalt protoporphyrin IX (CoPP), a known inducer of heme oxygenase-1, inhibits formation of the thrombus in response to laser ablation of endothelium in cremaster arterioles, whereas tin protoporphyrin IX (SnPP), a heme oxygenase-1 inhibitor, leads to enhanced thrombus formation (42). Interestingly, in a murine model of aorta allotransplantation, the thrombus was formed when aortas from $H m o x 1^{-1-}$ were grafted (43). The effect of the lack of Hmoxl was rescued with carbon monoxide releasing molecule-2 (CORM-2) (43). Moreover, administration of hemin, which not only induces Hmox 1 but also promotes oxidative stress, resulted in faster clot formation in response to ferric chloride in $H m o x 1^{-/-}$mice than in Hmox $1^{+/+}$mice, which was not observed under basal conditions (44). Noteworthy, in animals with a normal level of Hmox1 hemin may have a protective activity. Prophylactic treatment of Wistar rats with hemin reduced carotid thrombus formation in response to the electric stimulation (45). A similar observation was found in the mouse cremaster microvascular circulation, where hemin delayed formation of the thrombus in response to ferric chloride (46).

Despite the fact that the majority of functional studies regarding the role of Hmox 1 in thrombus formation were conducted in the context of occlusive thrombosis, there are several findings that implicate Hmoxl in AAA pathobiology. Of note, expression of Hmox 1 is increased in rat aorta on days 7 and 10 after AAA induction with elastase (47). Enhanced expression of Hmox1 prevents endothelial cell apoptosis and facilitates endothelial proliferation (32). By contrast, upregulation of Hmox1 in vascular SMCs induces p53 expression and promotes apoptosis (48). Noteworthy, increased SMC death and a high level of p53 is a common feature of AAA lesions and the weakening vessel wall (49). Furthermore, carbon monoxide inhibits the rat aortic SMC proliferation under hypoxic conditions in response to endothelin-1 (34). Moreover, probucol, which is used to prevent restenosis, increases Hmoxl levels in SMCs and therefore inhibits their proliferation (50). The diverse effects that Hmox 1 and its enzymatic products may exert in the AAA setting (such as reducing thrombus formation, yet increasing SMC apoptosis) are summarized in Figure 3.

Importantly, the level of Hmox 1 expression in humans is modulated with the microsatellite polymorphism of the gene promoter (51). Namely, a longer promoter with more guanidine-thymidine (GT) repeats $(n \geq 29)$ results in lower basal expression of Hmox1 and weaker upregulation in response to stimuli (52). It was shown that human umbilical vein endothelial cells with a short Hmox1 promoter $(n \leq 23)$ survive better under oxidative stress, proliferate more effectively in response to vascular endothelial growth factor and produce less pro-inflammatory cytokines such as IL-1 $\beta$,
IL-6, and soluble intercellular adhesion molecule-1 (52). The frequency of carriers of the short GT repeat allele of the Hmox1 promoter was significantly lower in Austrian AAA patients than in coronary or peripheral artery disease-matched controls (53). Similarly, there was a higher frequency of the longer GT repeat allele of the Hmox 1 promoter in patients with cerebral aneurysms (54). This may suggest that a higher expression or inducibility of Hmox 1 may play a protective role against AAA development. By contrast, in a group of Croatian AAA patients, there was a higher frequency of the carriers of short GT repeats in the Hmox1 promoter than in the non-AAA group (55). Thus, the relation between AAA development and Hmox 1 promoter polymorphism requires further analysis.

\section{Role of NO and Nitroxidative Stress in Aortic Aneurysm Formation}

Nitric oxide (NO) can be produced by three nitric oxide synthases (NOS): endothelial - eNOS, neuronal - nNOS and inducible iNOS. In endothelium, NO is produced mainly by eNOS (Figure 4). Its release depends on the velocity of blood flow and the diameter of the vessel. In the cardiovascular system, NO regulates the blood flow as well as prevents platelet and leukocyte adhesion and aggregation $(33,56,57)$. Under laminar flow, there is a homogeneous thin layer (about $1-3 \mu \mathrm{m}$ ) of NO in close proximity to the arterial wall. However, under turbulent or semi-turbulent flow, the NO layer can be depleted (58). Therefore, NO production from the endothelium under turbulent flow is significantly higher than under laminar flow. Under this turbulent flow and under intensive production of NO, eNOS can become uncoupled, which leads to dysfunction of the endothelial cells $(58,59)$. This process is observed in many cardiovascular diseases including atherosclerosis, hypertension, stroke, diabetes, and aneurysm. The uncoupling of eNOS can be attributed to a shortage of substrates of eNOS (L-arginine and/ or oxygen) as well as cofactors of eNOS like tetrahydrobiopterin (THB) $(60,61)$. Uncoupled eNOS can concomitantly generate NO

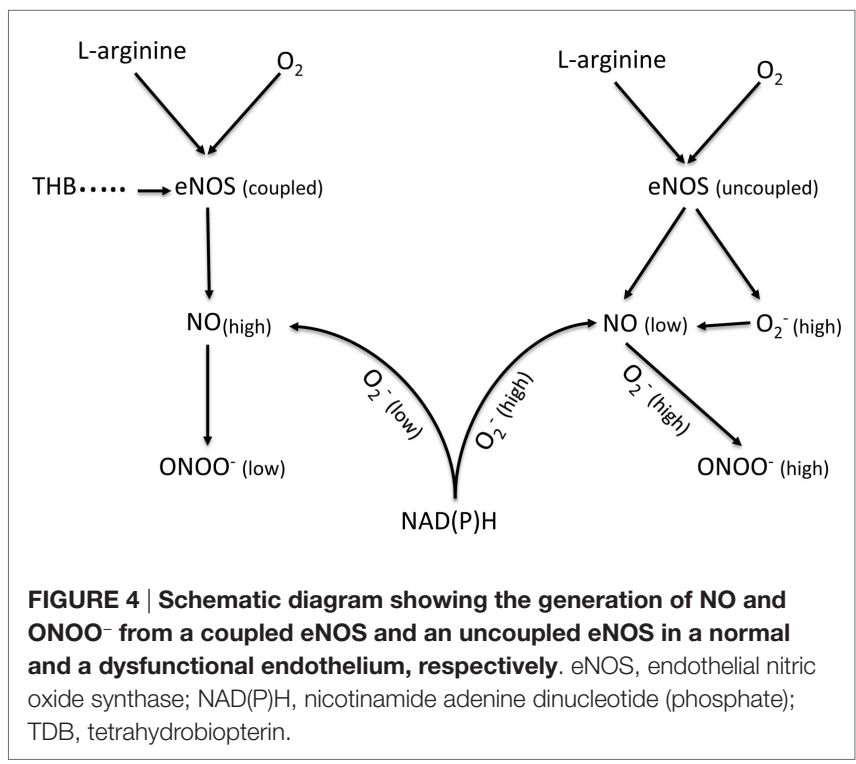


and superoxide $\left(\mathrm{O}_{2}^{-}\right)$. NO can react rapidly in a diffusion controlled reaction with $\mathrm{O}_{2}^{-}$to produce peroxynitrite $\left(\mathrm{ONOO}^{-}\right)$. Peroxynitrite is a short lived $\left(t_{1 / 2}<1 \mathrm{~s}\right)$ molecule with an oxidation power that is much higher than that of $\mathrm{NO}$ or $\mathrm{O}_{2}^{-}$. Therefore, high concentrations of $\mathrm{ONOO}^{-}$can cause significant damage to proteins, enzymes, and DNA in a biological milieu $(62,63)$.

The role of NO in the development of aneurysm is ambiguous and unclear. There are several studies concerning eNOS- and iNOSderived NO in the pathology of aneurysms performed on animal models and human beings (64-68). However, the results produced by these studies are very often contradictory. Aneurysmal degeneration is a result of biochemical and biomechanical processes, which finally lead to the partial destruction of the aortic wall (49). Nitric oxide and peroxynitrite may be involved in many of these processes. The effect of turbulent flow will be more pronounced with the increase in diameter and asymmetry of aneurysms (69). Based on our studies, the change of flow from laminar to turbulent would lead to a higher level of NO concentrations and a higher expression of eNOS $(62,63)$. However, an increase in eNOS expression does not always produce a higher level of bioavailable NO (diffusible NO, which can be involved in cellular signaling), because it is not usually accompanied by an increase in the levels of L-arginine or cofactors like THB. At an insufficient level of substrates and cofactors, the dimeric form of eNOS enzyme can be uncoupled and the net effect of uncoupled eNOS correlates inversely with the level of bioavailable $\mathrm{NO}$ and directly with $\mathrm{ONOO}^{-}$concentrations. Thus, while NO production by eNOS is known to play a protective role in the cardiovascular system by its vasodilatory effect, Gao et al. found that eNOS uncoupling/THB deficiency accelerated the formation of AAA in mice (64). Comparably, it has been suggested that eNOS deficiency increased in atherosclerosis in Western-type diet-food apoE knock-out mice and triggered spontaneous aortic aneurysms (66). Furthermore, NO may play a role in the MMP regulation in AAA: NO produced via eNOS inhibits MMP activity and inhibits SMC migration $(65,68)$.

Animal models demonstrated that inhibition of iNOS decreased NO generation and inhibited aneurysm formation. However, the opposite effect was also reported. Lee et al. demonstrated in animal models that iNOS does not play a requisite role in the process of elastase-induced experimental aneurysmal degeneration in mice (67). The authors also suggested that therapeutic treatment of aneurysms by inhibition of iNOS may have a deleterious effect. Most published studies on models of aneurysm indicate that iNOS expression increases while eNOS decreases during aneurysmal degeneration.

We believe that a likely reason for these confusing results is due to the heterogeneous distribution of NOS along the wall of an aneurysm. In our opinion, the type of flow (laminar versus turbulent) could be a determining factor, which will influence the kinetics of NO release, expression of eNOS and iNOS, and NO bioavailability in different segments of aneurysmal tissue. Therefore, one can assume that it is highly unlikely that a lateral NO distribution in the aneurysm will be homogeneous, but it will not be. Thus, analysis of a sample of aneurysm without information providing specific locations (coordinates) of the aneurysmal tissue may be flawed. An indication of NO production by iNOS has been closely associated with inflammation, which follows an increase in the dysfunction of the endothelium, the increase in eNOS uncoupling, and an increase in peroxynitrite and nitroxidative stress. It is well accepted that $\mathrm{ONOO}^{-}$is directly involved in the triggering of inflammation. Endothelial, bioavailable NO is cytoprotective, while peroxynitrite is cytotoxic. The balance between the concentrations of these two molecules has to be measured along the arterial wall at well-defined coordinates. These kinds of measurements have never been done and this is likely the reason for the very conflicting picture seen for the role of NO in the development of aneurysms. Recently, our laboratory developed a system of nanosensors (diameter of lower than $300 \mathrm{~nm}$ ), which can be placed near the endothelium of an aortic aneurysm for the simultaneous, in situ measurements of $\mathrm{NO}, \mathrm{ONOO}^{-}$, and $\mathrm{O}_{2}^{-}(62,63)$. The preliminary data obtained from these experiments indicate a substantial difference in the kinetics and concentration of the release of NO, as well as the release of the other components of nitroxidative stress at different segments of aneurysms. NO plays a significant role in the early events in aneurysm formation and this mechanism may not be related to hypertension. During this early event, uncoupled eNOS starts to produce significant concentrations of $\mathrm{ONOO}^{-}$, changing the balance between the cytoprotective $\mathrm{NO}$ and the cytotoxic $\mathrm{ONOO}^{-}(70)$. The $\mathrm{NO} / \mathrm{ONOO}^{-}$imbalance stimulates iNOS, which starts to produce uncontrollably high levels of $\mathrm{NO}$, as a protective measure. However, this increase in NO production by iNOS causes further uncoupling of eNOS due to local consumption of L-arginine. The net effect of these processes (nitroxidative stress) stimulates a cascade of events, which lead to the elevated generation of additional oxidative and nitroxidative species, including $\mathrm{O}_{2}^{-}, \mathrm{ONOO}^{-}$, and $\mathrm{H}_{2} \mathrm{O}_{2}$. The stimulation of $\mathrm{NAD}(\mathrm{P}) \mathrm{H}$, under this condition, contributes to the elevation of $\mathrm{O}_{2}^{-}$, oxidation of THB, and the further enhancement of $\mathrm{ONOO}^{-}$levels $(62,64)$.

Therefore, the low level of bioavailable $\mathrm{NO}$ and the high level of nitroxidative and oxidative stress can be considered as important factors in the initial stage of aneurysm development. This process can be similar to that observed in atherosclerosis. Nitroxidative stress can trigger several processes leading to the injuring of endothelial cells and SMCs, upregulation of chemotactic cytokines, upregulation of $\mathrm{NAD}(\mathrm{P}) \mathrm{H}$ and adhesion molecules, as well as activation of MMPs (71). All of these processes can contribute to vessel wall remodeling and breakdown. As the aneurysm develops further, NO is involved in the inhibition of smooth muscle proliferation, nitroxidative stress, and the change of angiogenic activities $(35,72)$. This may result in the serious destruction of extracellular matrix and elastic fibers. The net effect of $\mathrm{NO}$ and $\mathrm{ONOO}^{-}$action can be the thickening and weakening of the arterial wall and finally its rupture. We believe that the ratio of NO concentration to $\mathrm{ONOO}^{-}$concentration and non-homogenous distribution of oxidative/nitroxidative stress plays a crucial role in the development of the aneurysm.

\section{Role of Neutrophils in Aortic Aneurysm Formation}

The bulk amount of ROS and reactive nitrogen species (RNS) in AAA and ILT is produced by activated polymorphonuclear cells like neutrophils. Neutrophils have pro-oxidant activities via, e.g., NADPH oxidase and myeloperoxidase. Myeloperoxidase is a 
heme enzyme, which is expressed in $95 \%$ of polymorphonuclear neutrophils (PMNs). Both myeloperoxidase and NAPDH oxidase are primarily involved in the generation of ROS/RNS (73). RamosMozo et al. showed a decreased catalase activity in circulating PMNs as well as in plasma from AAA patients, indicating that neutrophils of AAA patients have a reduction in anti-oxidant enzymes (74). By contrast, $\mathrm{H}_{2} \mathrm{O}_{2}$ levels and MPO levels in isolated $\mathrm{PMN}$ were significantly higher than in controls. Therefore, a redox imbalance toward increased oxidative stress in AAA patients could be a key factor in AAA formation (74). However, PMNs do not only contribute to oxidative stress but also to proteolytic degradation of the aortic media and to adventitial inflammation (75). Importantly, PMN depletion showed a significant inhibition of experimental AAA formation thus pointing to the central role of neutrophils in AAA pathogenesis (76).

The luminal layer of the ILT is the predominant site of leukocyte retention. In the luminal ILT IL-8, a neutrophil chemotactic factor is released four times higher than in the AAA wall (77). Leukotriene B4 (LTB4) is another potent leukocyte chemoattractant and mediator of inflammation. Houard et al. showed thrombus-derived LTB4 as a mediator of neutrophil chemotaxis (78). Again, the luminal layer of the ILT had the highest activity. Furthermore, the alternative complement pathway was found to be activated in the AAA setting (79) and C5a had the specific ability to chemoattract neutrophils and trigger oxidative burst by inducing the release of CXC chemokines (80). Pagano et al. showed in a murine model that elastase-induced AAA is indeed complement (C3a, C5a) dependent (79). Neutrophils are 12 times more numerous in clots than in blood because these cells have a high affinity for the fibrin-fibronectin network. They bind to fibrin via integrins and to platelet-exposed P-selectin via the expression of the sialyl Lewis-X-containing polysaccharide ligand (81). Neutrophils are terminally differentiated cells, which undergo constitutive apoptosis after binding; this process is postponed upon NF- $\mathrm{KB}$ activation in neutrophils (82) as facilitated in the context of the ILT.

The presence of an ILT has been associated with a thinner arterial wall (21), more extensive elastolysis, a lower density of SMCs in the media, and a higher level of immuno-inflammation in the adventitia (19). This suggests that an important part of the protease activity originates from the ILT in contrast to the previously suspected direct generation within the AAA wall. The ILT is particularly rich in pro- and active forms of MMP-9 (83), and MMP-9-lipocalin complexes, which are of neutrophil origin (84). Localization of neutrophils in the luminal part of the thrombus is associated with increased levels of MMP-8, MMP-9, and elastase compared with other (medial and abluminal) layers of the ILT (36). Neutrophils release granular serine proteases such as urokinase plasminogen activator, elastase, proteinase 3 , and cathepsins from their azurophilic granules. MMP-9 and MMP-8 are released from gelatinase granules. The cysteine proteases are also potent elastolytic and collagenolytic enzymes associated with AAA development. Several cathepsins (85) and dipeptidyl peptidase I (86) have been reported to be elevated in AAA tissue, combined with a decrease in their cystatin inhibitors. Dipeptidyl peptidase I is a lysosomal cysteine protease, which is of central importance, as it promotes the activation of granule-associated serine proteases, including neutrophil elastase, cathepsin G, and proteinase 3 (87). Neutrophil proteases may essentially degrade all types of matrix fibrillar proteins and thus promote AAA progression and ultimate wall rupture. The site of final adventitial rupture is characterized by a high level of protease expression (88) and a prominent enrichment of leukocytes and focal neovascularization (89). Of interest, Lindholt et al. have reported a protective effect of calcification in the evolution of AAA, probably explained by the greater resistance of calcified tissue to proteolysis (90).

Abdominal aortic aneurysm biomarkers are of great scientific interest, as a specific biomarker for prediction of AAA rupture is urgently needed. There are no AAA-specific laboratory markers; however, neutrophil-related factors may have future prospects. Ramos-Mozo et al. showed that plasma levels of neutrophil gelatinase-associated lipocalin are increased in AAA patients and correlate with AAA growth, reflecting the potential activation of both resident and circulating neutrophils (91). Despite the fact that AAA-related biomarkers have the limitation of not being disease specific due to a strong connection to general atherosclerosis, MMP-9 levels were found to have a significant correlation with AAA diagnosis (92). In addition to the marker potential, neutrophils (and PMN-related factors) constitute a therapeutic target in AAA patients. Doxycycline can directly inhibit MMP activity, and it effectively suppresses the development of elastase-induced AAAs in preclinical models (93). In clinical trials, preoperative doxycycline therapy improved the proteolytic balance in human AAA by reducing aortic wall neutrophil content (94). Doxycycline treatment resulted in a 2.5-fold decrease of MMP-9 protein levels (95). Lindeman et al. could show a strongly reduced PMN and cytotoxic T-cell content of the aortic wall after a 2-week doxycycline treatment of AAA patients indicating that the doxycyclinemediated effects are not restricted to neutrophils (96).

\section{Treatment Indications}

Biodegradation of the abdominal aortic wall determines aneurysmal growth. Average growth rates of AAAs below $55 \mathrm{~mm}$ in size range from 2 to $3 \mathrm{~mm}$ per year. Larger AAAs are associated with higher growth rates (4). Most AAAs are asymptomatic, and the vast majority is detected occasionally during routine investigations. Risk factors for progression to rupture comprise hypertension, age, female sex, and persistent smoking (4). Finally, the life-threatening risk of rupture has to offset the operative mortality for aneurysm repair. For small fusiform AAAs (AAA diameter 30-39 mm), the 12 months risk of rupture is $0 \%$, and it is still about $1 \%$ in those cases when the AAA diameter ranges between $40-49 \mathrm{~mm}$ (4). As a consequence, several studies recommended pursuing a surveillance policy in these cases (97). However, the 12 months risk of rupture rises exponentially with further increase of the aortal maximum diameter. Consequently, the threshold for aortic repair is $50 \mathrm{~mm}$ for women and $55 \mathrm{~mm}$ for men (4).

Besides the diameter of the AAA, its morphology plays another important role in the decision for repair. Fusiform AAAs are thought to be less prone to rupture than saccular AAAs, or those with eccentric components (Figure 1). Peak wall stress, presence of an ILT (Figure 2), and AAA wall mechanics are the factors most implicated with rupture risk. Therefore, early repair has been advised in these cases (98). 
Symptomatic AAA is characterized by abdominal, back, or chest pain (99). Peripheral embolization with subsequent ischemia may be another sequel of AAAs with intraluminal thrombus (4). Peak wall stress is significantly greater in symptomatic or ruptured AAAs compared to asymptomatic AAAs according to a recent meta-analysis (98). As a consequence, early repair has been recommended in symptomatic patients $(4,98)$. Likewise, rapid aneurysm growth with more than $10 \mathrm{~mm}$ per year represents another indication for early repair (4). In conclusion, these recommendations aim to prevent AAA rupture, a life-threatening event with mortality rates of approximately $65-85 \%$ (100).

\section{Surgical Repair}

Thorough preoperative evaluation of the patient's comorbid diseases is a prerequisite for any type of surgical repair as its outcome essentially determines the decision between open or endovascular repair. Second, optimization of the treatment for various comorbidities should be obtained (4). Moreover, computed tomography (CT) or magnetic resonance angiograms are necessary to outline the morphological characteristics of AAAs for devising the operative strategies in open surgical repair (OSR) as well as for selection of the appropriate stent graft for endovascular aortic repair (EVAR). OSR is the mainstay in elective AAA cases. In general, tube grafts (Figure 5A) are preferred to bifurcated grafts, due to reduced dissection with less risk of injury to adjacent structures and consecutively shorter operating time (4). In case of additional iliac artery aneurysms or concomitant iliac arterial occlusive disease, indication for a bifurcated graft is given (Figure 5B). Since the introduction of EVAR via a transfemoral approach by Volodos in 1984 (101), this technique has become of wide-spread use (Figure 6).
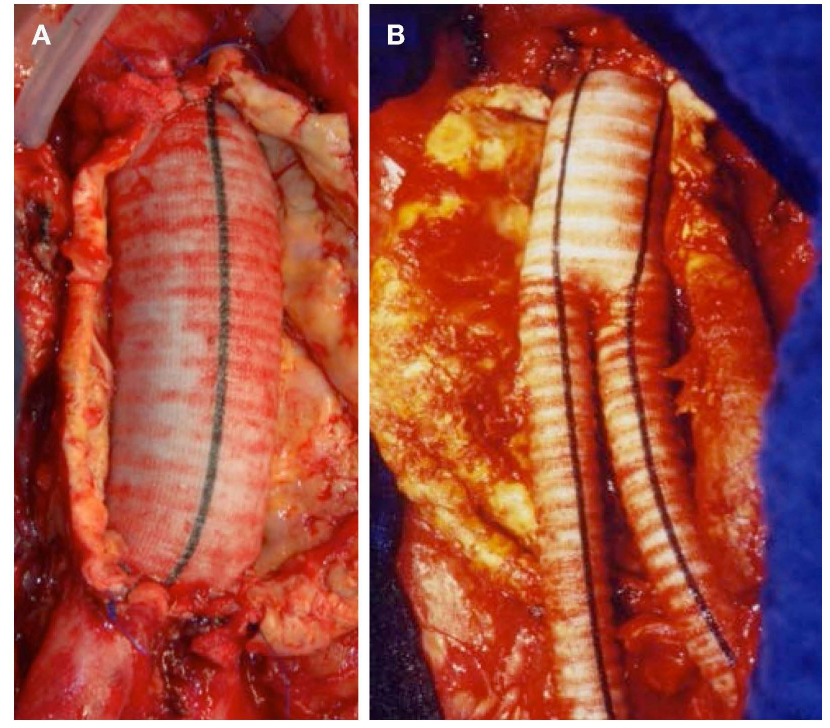

FIGURE 5 | (A) Successful exclusion of an infrarenal AAA by a tube graft. lliac bifurcation intact. (B) Successful exclusion of an infrarenal AAA by a bifurcated stent graft.
An advantage of EVAR over OSR is less surgical trauma. Moreover, general anesthesia can be avoided. EVAR, however, requires adequate aortic and iliac fixation sites for effective sealing and fixation (4). Tortuous iliac arteries or extreme kinking of the aorta may prevent from adequate insertion or fixation of the stent graft in up to $40 \%$ of the patients. Endoleak after EVAR is a common complication in up to $25 \%$ of patients (4). In general, AAA patients suffer from a pro-thrombotic tendency. While the incidence of AAA-related disseminated intravascular coagulation (DIC) prior to surgery is rare and may be resolved upon AAA repair, the occurrence of DIC as a perioperative coagulopathy is a more frequent complication (102). In addition, a high incidence of venous thrombosis is observed after elective AAA repair despite systematic heparin application (103) and both coagulopathy as well as a hyperfibrinolysis are similarly encountered in ruptured AAA repair (104). It has been subject of investigation whether the two types of surgical intervention (OSR versus EVAR) differ in their hemostasis effects (27). Both were found to further aggravate the pro-coagulant and hyperfibrinolytic state of AAA patients in the initial post-operative period $(105,106)$ while reducing the circulating markers of deregulated hemostasis/fibrinolysis several months after AAA repair (107). Despite the fact that EVAR represents a smaller surgical trauma, a number of studies observed that EVAR as compared to open surgery led to higher marker levels in the immediate perioperative phase as well as the long-term period (108). This indicates that the inherent procedure and materials of EVAR may extend the hemostatic imbalance after AAA repair.

With respect to overall outcome, meta-analyses of prospective, randomized, controlled trials showed that 30-day mortality was higher in OSR (3.2-4.2\%) versus EVAR (1.2-1.4\%) in elective AAAs (109-111). However, there were no differences in the long-term ( $>4$ years) all-cause mortality between EVAR $(37.3 \%)$ and OSR $(37.8 \%)(109,110,112)$. Causes of deaths were primarily cardiovascular events with similar incidences of cardiac death and

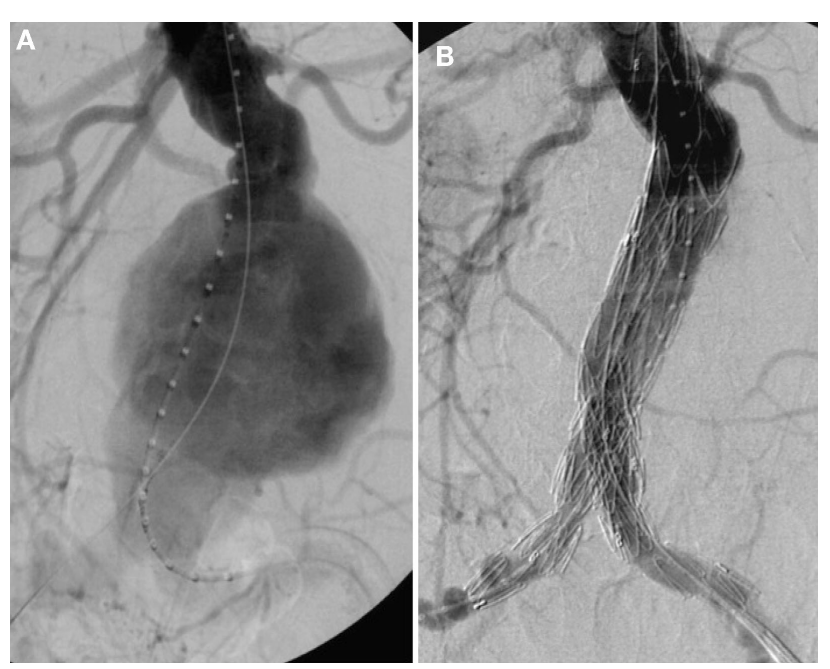

FIGURE 6 | (A) Invasive angiography prior to endovascular repair (EVAR): rupture of an infrarenal AAA. (B) Final angiography after EVAR: successful exclusion of the ruptured AAA by a bifurcated stent graft; no endoleak visible. 
fatal stroke, and malignant diseases $(109,112)$. Moreover, there were no significant differences in aneurysm-related mortality. Re-intervention rates, however, were significantly higher and more aortic related after EVAR (18.9\%) compared to OSR (9.3\%) (110).

The incidence of ruptured AAAs ranges between 6 and 18 per 100000 person-years in Western countries (4). The overall mortality rate is extremely high with up to $80-90 \%$. AAA rupture, defined as bleeding outside the adventitia of the dilated aortic wall, is classified into free rupture into the peritoneal cavity with extremely poor outcome or retroperitoneal rupture. Treatment strategies are of importance in aortic surgery, as clamping of the aorta is connected with a massive lower torso ischemia. Pre- (113) and post-conditioning (114) should activate the endogenous anti-oxidant defense mechanisms. Additionally, early infusion of radical scavengers plus L-arginine and cofactors $(59,61,115,116)$ play an important role to ameliorate deleterious consequences. Following these strategies, a reduction of 30-day mortality rates (52\%) was noticed (117). In our own studies, the 90 -day mortality rate for patients receiving OSR was $29 \%$ (118). In the last decade, a progressive increase in the proportion of patients managed by EVAR in case of ruptured AAAs was observed. Importantly, it has been shown that successful exclusion of ruptured AAAs by EVAR is feasible. Several studies showed significantly lower 30-day mortality rates after EVAR (24\%) compared to OSR $(52 \%)(111,117)$. The survival advantage for EVAR after ruptured AAA persisted during the first 5 years after repair, but was lost after that period. The estimated 5-year survival was 44 and 39\% for EVAR and OSR, respectively (117). By contrast, a recent meta-analysis including only randomized controlled trials failed to show superior outcome after EVAR compared to OSR (119). Moreover, long-term data are lacking for both survival and complications (119).

In conclusion, evaluation of the literature on OSR versus EVAR in both elective and ruptured AAAs failed to show superiority of one of these treatments in the long run, because randomized controlled trials do not consider the various risk factors, which account for the final outcome. Therefore, the tailored approach attributing geriatric patients with multiple morbidities to EVAR resulted in better outcome rates - at least initially $(120,121)$. In individuals considered unfit for OSR, no difference between EVAR and the non-intervention group with regard to all-cause mortality ( $21 \%$ in each group), with higher aneurysm-related deaths in the non-intervention group have been described (109). This finding may prompt us to avoid excessive surgery in geriatric and high-risk patients with multiple comorbidities. Future research, however, should aim at predictors for AAA growth and rupture. New biochemical markers along with functional imaging may help to select patients who are at risk at an early stage.

\section{Pharmacological Treatment Options}

Based on the outlined pathomechanism of disease, various pharmacological treatments are offered to AAA patients in addition to surgical intervention, which is limited to the progressed state (Figure 7). According to the European Society for Vascular Surgery guidelines for the management of AAA, statins and anti-platelet drugs should be used in patients diagnosed with AAA (4). Statins should be started 1 month before intervention to reduce cardiovascular morbidity and should be continued in the perioperative period for an indefinite duration; while aspirin at low doses should be prescribed on diagnosis and continued through the perioperative period unless a contradiction exists (4). However, only statins were indicated to both reduce cardiovascular mortality in AAA patients and to slow the rate of AAA growth. On the contrary, among the drugs that do not affect AAA growth but may be indicated for comorbidities are beta-blockers, angiotensinconverting enzyme (ACE) inhibitors, and AT1-receptor antagonists (122).

Abdominal aortic aneurysm is thought to be an inflammatory disease as patients with AAA exhibit increased values of inflammatory parameters such as C-reactive protein (123), or cytokines like tumor necrosis factor alpha (TNF- $\alpha$ ) (77). Indeed, AAA and ILT are sources of physiologically active cells, including macrophages, T-cells, B-cells, and neutrophils that produce large amounts of messenger molecules (124). SMCs and endothelial cells in the AAA wall as well as red blood cells and platelets in the intraluminal thrombus are a source of free oxygen and nitrogen radicals. When activated platelets produce intracellular superoxide anion via NADPH oxidase, it conversely increases platelet recruitment favoring thrombus formation (125).

\section{Statins}

The guidelines are based on experimental and clinical evidence of the positive effect of statins in AAA prevention and treatment. It was reported that statins may prevent aneurysm formation in animal models (126). Moreover, some observational studies in humans presented a 50\% reduction in AAA expansion rate (127), and an association between statin therapy and a risk of AAA rupture (6). Also, a randomized trial reported that fluvastatin (80 mg daily for 30 days before surgery and continued until at least 30 days after surgery) halved both the primary 30 -day outcome of post-operative myocardial ischemia and the secondary outcome of non-fatal myocardial infarction and cardiovascular death (128). A recent large meta-analysis showed that statins reduce the rate of progression of AAA (129). The meta-analysis by Galinanes et al. (130) reported that 1 week of statins administered to patients undergoing OSR or EVAR was associated with improved survival during 1 year after surgery and a decreased incidence of lower extremity embolic complications after EVAR.

In our previous report, we showed that simvastatin decreased the rate of free radical formation and the content of pro-inflammatory molecules like TNF- $\alpha$ in the aneurysmal wall (131). Therefore, protection of the AAA wall from ROS may be an important factor in the reduced AAA rupture risk. Furthermore, patients with a higher baseline $\mathrm{C}$-reactive protein level respond better to statin therapy and have a lower absolute vascular risk than those without statins, as the findings of the JUPITER trial documented (132). The anti-inflammatory effect of statins may be in part connected with their influence on pro-inflammatory signaling pathways. Simvastatin taken for at least 6 months decreased the activity of NF- $\kappa \mathrm{B}$ and ERK1/2 signaling pathways in the aortic wall of AAA patients $(131,133)$. A reduction in NF- $\kappa$ B activity under statins may be in part related with modulation of NF- $\kappa \mathrm{B}$ in infiltrating $\mathrm{T}$ helper cells and CD40 signaling in SMCs and mononuclear cells (134), resulting in lower synthesis and release of IL-6 and 


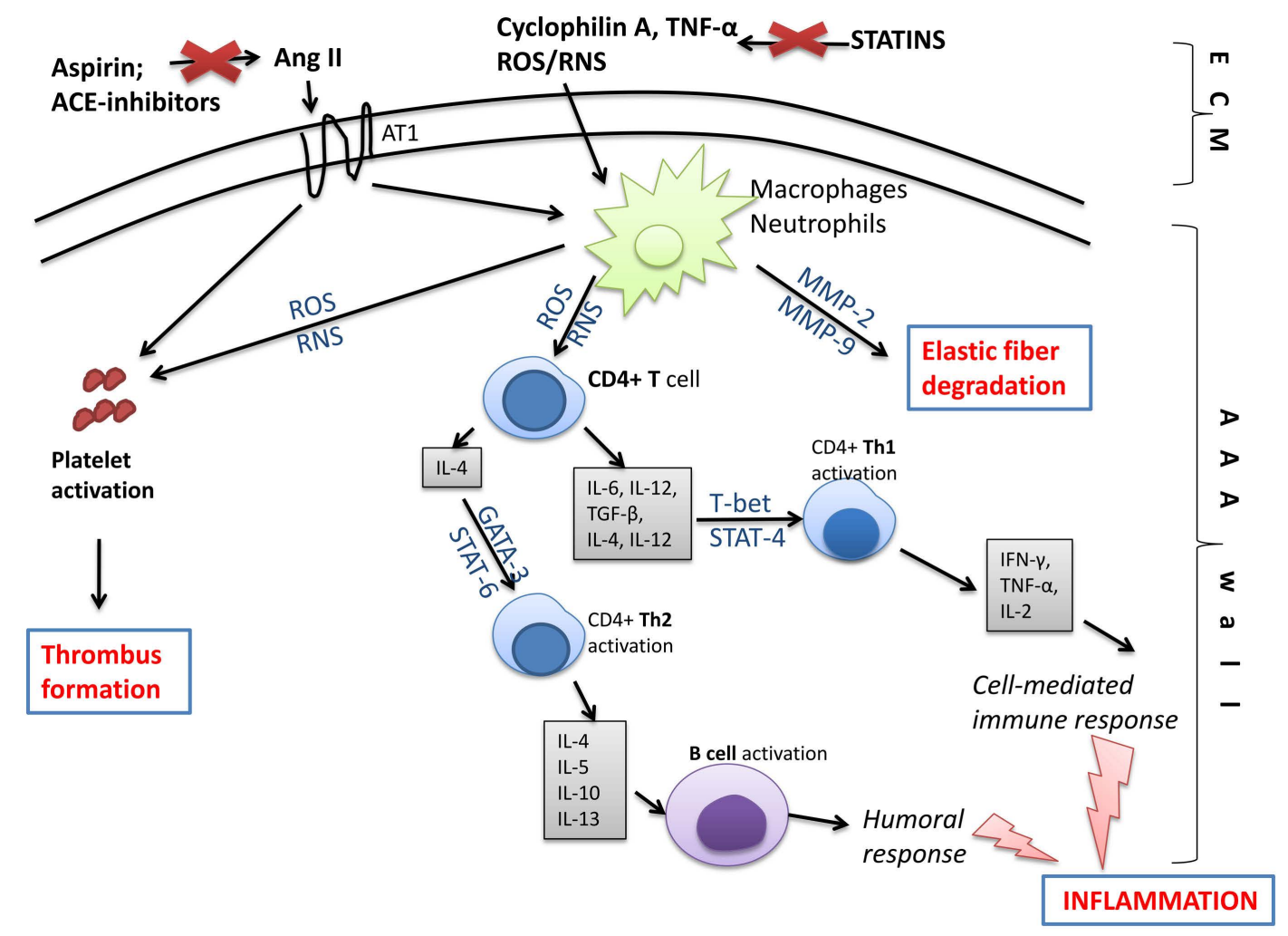

FIGURE 7 | Molecular changes in the aneurysmal wall, which may be targeted by pharmacological treatment. Compounds generated in the extracellular matrix (ECM) like free oxygen or nitrogen species (ROS/RNS), inflammatory cytokines, e.g., tumor necrosis factor alpha (TNF- $\alpha$ ) or cyclophilin A, and angiotensin II (through angiotensin receptor 1; AT1) stimulate inflammatory cells like macrophages or neutrophils, and platelets inside the AAA wall. Next, macrophages/neutrophils act on $\mathrm{T}$ and B lymphocytes initiating humoral and cell-mediated immune responses and leading to inflammation. As a consequence, pro-inflammatory signaling pathways involving NF-kB, T-bet, STAT-4, STAT-6, or GATA-3 are activated and a large amount of pro-inflammatory cytokines is released. Moreover, activated leukocytes produce matrix metalloproteinases (MMPs), which degrade elastic fibers inside the AAA wall. The activation of AT1 receptor and increased production of ROS/RNS by leukocytes activate platelets that form the intraluminal thrombus. Those changes, however, may be slowed down or eliminated by statins, anti-platelet drugs, or ACE inhibitors. ACE inhibitors, angiotensin-converting-enzyme inhibitors; Ang II, angiotensin II; AT1, angiotensin II receptor type 1; GATA, trans-acting T cell-specific transcription factor; MMP, matrix metalloproteinase; ROS, reactive oxygen species; RNS, reactive nitrogen species; STAT, signal transducer and activator of transcription; TGF- $\beta$, transforming growth factor beta; Th, T helper cell; TNF- $\alpha$, tumor necrosis factor alpha.
IL-8 (135). Recently, van de Meij et al. (124) confirmed previous findings that patients who underwent AAA repair treated with simvastatin and atorvastatin at clinical doses had a reduced tissue content of macrophage-related markers and NF- $\mathrm{KB}$ dependent inflammatory molecules such as IL-6 and MCP-1, however, without a decrease in macrophage content.

Furthermore, inflammatory mediators regulate the expression and activity of MMPs released mainly by activated neutrophils and macrophages. In animal models, statin therapy suppressed the extent of AAA formation by $25 \%$, and the incidence of AAA by $30 \%$ (136). The effect was associated with a reduction in MMP-9 protein and gene expression. In clinical trials, simvastatin was found to significantly lower MMP-9 concentrations by $40 \%$ within the aneurysm wall compared to placebo (137). Importantly, MMPs are inhibited when complexed with tissue inhibitors of MMPs (TIMPs). It was reported that MMP-9 and TIMP-1 as well as MMP-2 and TIMP-2 correlate with ILT thickness in patients with AAA (20). Therefore, statins may have beneficial effects to slow AAA growth.

\section{Anti-Platelet Therapy}

Meta-analyses of randomized trials on primary and secondary prevention of AAA with anti-platelet therapy suggested that all patients diagnosed with AAA should be started on aspirin therapy at the time of AAA diagnosis as the use of low-dose aspirin may be associated with a reduction in all vascular deaths (138). Recent epidemiologic data indicate that the initiation of lifelong aspirin therapy should be considered as soon as a diagnosis of AAA is made (139). However, a retrospective study, which investigated aortic aneurysm cases between 1999 and 2006 from the National Health Insurance Research Database found no association between low-dose aspirin exposure and mortality or exacerbation in different types of aortic aneurysms (140).

Animal studies also showed that aspirin may significantly reduce both aortic plaque size and thrombus formation after vessel injury (141). Those effects may be in part mediated by the antioxidant effect of aspirin in atherosclerotic vessels (142). Aspirin treatment also leads to a reduction in free radical stress evident by 
decreased lipid peroxidation and significantly prevented reduction in glutathione content in endothelial cells of hypercholesterolemic animals (143). Therefore, based on animal models, anti-platelet therapy is expected to be beneficial to AAA patients.

\section{ACE Inhibitors}

Activation of the renin-angiotensin system has been implicated in the genesis of several cardiovascular disorders including AAA (144). Angiotensin II (Ang II) is strongly upregulated in human aortic aneurysms, and the Ang II increase is mediated by pathways dependent on ACE and chymase (145). In experimental studies, ACE inhibitors were found to reduce AAA rate (146), and in a retrospective clinical study, they were associated with a reduction in the risk of AAA rupture (147). However, there are controversial data. Some studies indicated that AAA patients treated with ACE inhibitors, but not those treated with other anti-hypertensives, seemed to be less likely to present with ruptured AAA as a recent Canadian study showed (147). By contrast, Wilmink et al. did not confirm the beneficial effect of ACE inhibitors on AAA progression (148), while others found a reverse, negative effect of ACE inhibitors on AAA (149).

Recently, Kortekaas et al. (150) presented results where patients treated with the ACE inhibitor ramipril ( $5 \mathrm{mg} /$ day, for 4 weeks) had significantly lower levels of NF- $\mathrm{KB}$ and Ang II activity in AAA tissue and a lower content of IL- 8 and MCP-1. The effect of ACE inhibitors on inflammatory mediators may result in a change of cell activation and, for instance, a shift in macrophage signature

\section{References}

1. Sonesson B, Lanne T, Hansen F, Sandgren T. Infrarenal aortic diameter in the healthy person. Eur J Vasc Surg (1994) 8(1):89-95. doi:10.1016/ S0950-821X(05)80127-6

2. Makrygiannis G, Courtois A, Drion P, Defraigne JO, Kuivaniemi H, Sakalihasan N. Sex differences in abdominal aortic aneurysm: the role of sex hormones. Ann Vasc Surg (2014) 28(8):1946-58. doi:10.1016/j.avsg.2014.07.008

3. Takayama T, Yamanouchi D. Aneurysmal disease: the abdominal aorta. Surg Clin North Am (2013) 93(4):877-91, viii. doi:10.1016/j.suc.2013.05.005

4. Moll FL, Powell JT, Fraedrich G, Verzini F, Haulon S, Waltham M, et al. Management of abdominal aortic aneurysms clinical practice guidelines of the European society for vascular surgery. Eur J Vasc Endovasc Surg (2011) 41(Suppl 1):S1-58. doi:10.1016/j.ejvs.2010.09.011

5. Li ZZ, Dai QY. Pathogenesis of abdominal aortic aneurysms: role of nicotine and nicotinic acetylcholine receptors. Mediators Inflamm (2012) 2012:103120. doi:10.1155/2012/103120

6. Gokani VJ, Sidloff D, Bath MF, Bown MJ, Sayers RD, Choke E. A retrospective study: factors associated with the risk of abdominal aortic aneurysm rupture. Vascul Pharmacol (2015) 65-66:13-6. doi:10.1016/j.vph.2014.11.006

7. Wong YY, Flicker L, Yeap BB, McCaul KA, Hankey GJ, Norman PE. Is hypovitaminosis D associated with abdominal aortic aneurysm, and is there a dose-response relationship? Eur J Vasc Endovasc Surg (2013) 45(6):657-64. doi:10.1016/j.ejvs.2013.03.015

8. Hinterseher I, Gabel G, Corvinus F, Luck C, Saeger HD, Bergert H, et al. Presence of Borrelia burgdorferi sensu lato antibodies in the serum of patients with abdominal aortic aneurysms. Eur J Clin Microbiol Infect Dis (2012) 31(5):781-9. doi:10.1007/s10096-011-1375-y

9. Bjorck M, Wanhainen A. Pathophysiology of AAA: heredity vs environment. Prog Cardiovasc Dis (2013) 56(1):2-6. doi:10.1016/j.pcad.2013.05.003

10. Helgadottir A, Thorleifsson G, Magnusson KP, Gretarsdottir S, Steinthorsdottir $\mathrm{V}$, Manolescu A, et al. The same sequence variant on 9p21 associates with toward a predominance of alternatively activated macrophages. This may at least in part, account for the reduced expression of the proteases MMP-9, cathepsin L, and S, which are all considered instrumental in the process of AAA growth (85). Moreover, ACE inhibitors influence elastolytic MMP levels in the AAA wall to reduce elastin degradation within the vessel (146).

\section{Conclusion}

Substantial progress has been made in recent years in understanding the process of AAA development and progression. The ILT has emerged as a major player, which "entraps" leukocytes, in particular neutrophils, to create a pro-oxidant and proteolytic environment that leads to vessel wall destabilization. The early processes of aneurysm development may be particularly sensitive to changes in the pathways controlling oxidative or nitroxidative stress where localized deregulation may induce endothelial and SMC dysfunction and promote thrombus formation. Thus, pharmacological treatment options for AAA patients progressively incorporate anti-oxidant, anti-inflammatory, and antiproteolytic drug effects in addition to cholesterol, hemostasis, or blood pressure control. The need for surgical repair is carefully evaluated based on disease progression, morphological AAA characteristics, and patient comorbidities to avoid unnecessary risks. Predictive markers such as D-dimer for AAA growth are required to evaluate the risk for imminent rupture and further improve disease control. myocardial infarction, abdominal aortic aneurysm and intracranial aneurysm Nat Genet (2008) 40(2):217-24. doi:10.1038/ng.72

11. Saratzis A, Bown MJ. The genetic basis for aortic aneurysmal disease. Heart (2014) 100(12):916-22. doi:10.1136/heartjnl-2013-305130

12. Halushka MK. Single gene disorders of the aortic wall. Cardiovasc Pathol (2012) 21(4):240-4. doi:10.1016/j.carpath.2011.09.004

13. O'Leary SA, Kavanagh EG, Grace PA, McGloughlin TM, Doyle BJ. The biaxial mechanical behaviour of abdominal aortic aneurysm intraluminal thrombus: classification of morphology and the determination of layer and region specific properties. JBiomech (2014) 47(6):1430-7. doi:10.1016/j.jbiomech.2014.01.041

14. Vorp DA, Mandarino WA, Webster MW, Gorcsan J III. Potential influence of intraluminal thrombus on abdominal aortic aneurysm as assessed by a new non-invasive method. Cardiovasc Surg (1996) 4(6):732-9. doi:10.1016/ S0967-2109(96)00008-7

15. Cervantes J, Martinez R, Perez-Garcia D. Acute thrombosis of abdominal aortic aneurysm. An uncommon entity. JCardiovasc Surg (Torino) (1985) 26(6):598-601.

16. Wang DH, Makaroun M, Webster MW, Vorp DA. Mechanical properties and microstructure of intraluminal thrombus from abdominal aortic aneurysm. J Biomech Eng (2001) 123(6):536-9. doi:10.1115/1.1411971

17. Adolph R, Vorp DA, Steed DL, Webster MW, Kameneva MV, Watkins SC. Cellular content and permeability of intraluminal thrombus in abdominal aortic aneurysm. J Vasc Surg (1997) 25(5):916-26. doi:10.1016/S0741-5214(97)70223-4

18. Liu O, Jia L, Liu X, Wang Y, Wang X, Qin Y, et al. Clopidogrel, a platelet $\mathrm{P} 2 \mathrm{Y} 12$ receptor inhibitor, reduces vascular inflammation and angiotensin II induced-abdominal aortic aneurysm progression. PLoS One (2012) 7(12):e51707. doi:10.1371/journal.pone.0051707

19. Kazi M, Thyberg J, Religa P, Roy J, Eriksson P, Hedin U, et al. Influence of intraluminal thrombus on structural and cellular composition of abdominal aortic aneurysm wall. J Vasc Surg (2003) 38(6):1283-92. doi:10.1016/s0741

20. Khan JA, Abdul Rahman MN, Mazari FA, Shahin Y, Smith G, Madden L, et al. Intraluminal thrombus has a selective influence on matrix metalloproteinases and their inhibitors (tissue inhibitors of matrix metalloproteinases) in the wall of 
abdominal aortic aneurysms. Ann Vasc Surg (2012) 26(3):322-9. doi:10.1016/j. avsg.2011.08.015

21. Vorp DA, Lee PC, Wang DH, Makaroun MS, Nemoto EM, Ogawa S, et al. Association of intraluminal thrombus in abdominal aortic aneurysm with local hypoxia and wall weakening. J Vasc Surg (2001) 34(2):291-9. doi:10.1067/ mva.2001.114813

22. Thubrikar MJ, Robicsek F, Labrosse M, Chervenkoff V, Fowler BL. Effect of thrombus on abdominal aortic aneurysm wall dilation and stress. J Cardiovasc Surg (Torino) (2003) 44(1):67-77.

23. Meyer CA, Guivier-Curien C, Moore JE Jr. Trans-thrombus blood pressure effects in abdominal aortic aneurysms. J Biomech Eng (2010) 132(7):071005. doi:10.1115/1.4001253

24. Speelman L, Schurink GW, Bosboom EM, Buth J, Breeuwer M, van de Vosse FN, et al. The mechanical role of thrombus on the growth rate of an abdominal aortic aneurysm. J Vasc Surg (2010) 51(1):19-26. doi:10.1016/j.jvs.2009.08.075

25. Moxon JV, Padula MP, Clancy P, Emeto TI, Herbert BR, Norman PE, et al. Proteomic analysis of intra-arterial thrombus secretions reveals a negative association of clusterin and thrombospondin-1 with abdominal aortic aneurysm. Atherosclerosis (2011) 219(2):432-9. doi:10.1016/j.atherosclerosis.2011.08.013

26. Starlinger P, Moll HP, Assinger A, Nemeth C, Hoetzenecker K, Gruenberger B, et al. Thrombospondin-1: a unique marker to identify in vitro platelet activation when monitoring in vivo processes. J Thromb Haemost (2010) 8(8):1809-19. doi:10.1111/j.1538-7836.2010.03908.x

27. Davies RS, Abdelhamid M, Wall ML, Vohra RK, Bradbury AW, Adam DJ. Coagulation, fibrinolysis, and platelet activation in patients undergoing open and endovascular repair of abdominal aortic aneurysm. J Vasc Surg (2011) 54(3):865-78. doi:10.1016/j.jvs.2011.04.010

28. Sidloff DA, Stather PW, Choke E, Bown MJ, Sayers RD. A systematic review and meta-analysis of the association between markers of hemostasis and abdominal aortic aneurysm presence and size. J Vasc Surg (2014) 59(2):528-35. doi:10.1016/j. jvs.2013.10.088

29. Siennicka A, Drozdzynska M, Chelstowski K, Cnotliwy M, Jastrzebska M. Haemostatic factors and intraluminal thrombus thickness in abdominal aortic aneurysm. Is secondary fibrinolysis relevant? J Physiol Pharmacol (2013) 64(3):321-30.

30. Golledge J, Muller R, Clancy P, McCann M, Norman PE. Evaluation of the diagnostic and prognostic value of plasma D-dimer for abdominal aortic aneurysm. Eur Heart J (2011) 32(3):354-64. doi:10.1093/eurheartj/ehq171

31. Lindblad B, Borner G, Gottsater A. Factors associated with development of large abdominal aortic aneurysm in middle-aged men. Eur J Vasc Endovasc Surg (2005) 30(4):346-52. doi:10.1016/j.jejvs.2005.04.021

32. Loboda A, Jazwa A, Grochot-Przeczek A, Rutkowski AJ, Cisowski J, Agarwal A, et al. Heme oxygenase- 1 and the vascular bed: from molecular mechanisms to therapeutic opportunities. Antioxid Redox Signal (2008) 10(10):1767-812. doi:10.1089/ars.2008.2043

33. Vallance P, Patton S, Bhagat K, MacAllister R, Radomski M, Moncada S, et al. Direct measurement of nitric oxide in human beings. Lancet (1995) 346(8968):153-4. doi:10.1016/S0140-6736(95)91211-8

34. Morita T, Mitsialis SA, Koike H, Liu Y, Kourembanas S. Carbon monoxide controls the proliferation of hypoxic vascular smooth muscle cells. J Biol Chem (1997) 272(52):32804-9. doi:10.1074/jbc.272.52.32804

35. Napoli C, Paolisso G, Casamassimi A, Al-Omran M, Barbieri M, Sommese L, et al. Effects of nitric oxide on cell proliferation: novel insights. J Am Coll Cardiol (2013) 62(2):89-95. doi:10.1016/j.jacc.2013.03.070

36. Fontaine V, Touat Z, Mtairag el M, Vranckx R, Louedec L, Houard X, et al. Role of leukocyte elastase in preventing cellular re-colonization of the mural thrombus. Am J Pathol (2004) 164(6):2077-87. doi:10.1016/S0002-9440(10)63766-2

37. Brune $B$, Ullrich V. Inhibition of platelet aggregation by carbon monoxide is mediated by activation of guanylate cyclase. Mol Pharmacol (1987) 32(4):497-504.

38. Fujita T, Toda K, Karimova A, Yan SF, Naka Y, Yet SF, et al. Paradoxical rescue from ischemic lung injury by inhaled carbon monoxide driven by derepression of fibrinolysis. Nat Med (2001) 7(5):598-604. doi:10.1038/87929

39. Matsumoto H, Ishikawa K, Itabe H, Maruyama Y. Carbon monoxide and bilirubin from heme oxygenase-1 suppresses reactive oxygen species generation and plasminogen activator inhibitor-1 induction. Mol Cell Biochem (2006) 291(1-2):21-8. doi:10.1007/s11010-006-9190-y

40. True AL, Olive M, Boehm M, San H, Westrick RJ, Raghavachari N, et al. Heme oxygenase-1 deficiency accelerates formation of arterial thrombosis through oxidative damage to the endothelium, which is rescued by inhaled carbon monoxide. Circ Res (2007) 101(9):893-901. doi:10.1161/CIRCRESAHA.107.158998

41. Tracz MJ, Juncos JP, Grande JP, Croatt AJ, Ackerman AW, Katusic ZS, et al. Induction of heme oxygenase- 1 is a beneficial response in a murine model of venous thrombosis. Am J Pathol (2008) 173(6):1882-90. doi:10.2353/ ajpath.2008.080556

42. Johns DG, Zelent D, Ao Z, Bradley BT, Cooke A, Contino L, et al. Hemeoxygenase induction inhibits arteriolar thrombosis in vivo: effect of the non-substrate inducer cobalt protoporphyrin. Eur J Pharmacol (2009) 606(1-3):109-14 doi:10.1016/j.ejphar.2008.12.030

43. Chen B, Guo L, Fan C, Bolisetty S, Joseph R, Wright MM, et al. Carbon monoxide rescues heme oxygenase-1-deficient mice from arterial thrombosis in allogeneic aortic transplantation. Am J Pathol (2009) 175(1):422-9. doi:10.2353/ ajpath.2009.081033

44. Peng L, Mundada L, Stomel JM, Liu JJ, Sun J, Yet SF, et al. Induction of heme oxygenase-1 expression inhibits platelet-dependent thrombosis. Antioxid Redox Signal (2004) 6(4):729-35. doi:10.1089/1523086041361677

45. Desbuards N, Rochefort GY, Schlecht D, Machet MC, Halimi JM, Eder V, et al. Heme oxygenase-1 inducer hemin prevents vascular thrombosis. Thromb Haemost (2007) 98(3):614-20.

46. Lindenblatt N, Bordel R, Schareck W, Menger MD, Vollmar B. Vascular heme oxygenase-1 induction suppresses microvascular thrombus formation in vivo. Arterioscler Thromb Vasc Biol (2004) 24(3):601-6. doi:10.1161/01. ATV.0000118279.74056.8a

47. Yajima N, Masuda M, Miyazaki M, Nakajima N, Chien S, Shyy JY. Oxidative stress is involved in the development of experimental abdominal aortic aneurysm: a study of the transcription profile with complementary DNA microarray. J Vasc Surg (2002) 36(2):379-85. doi:10.1067/mva.2002.124366

48. Liu XM, Chapman GB, Wang H, Durante W. Adenovirus-mediated heme oxygenase-1 gene expression stimulates apoptosis in vascular smooth muscle cells. Circulation (2002) 105(1):79-84. doi:10.1161/hc0102.101369

49. Lopez-Candales A, Holmes DR, Liao S, Scott MJ, Wickline SA, Thompson RW. Decreased vascular smooth muscle cell density in medial degeneration of human abdominal aortic aneurysms. Am J Pathol (1997) 150(3):993-1007.

50. Deng YM, Wu BJ, Witting PK, Stocker R. Probucol protects against smooth muscle cell proliferation by upregulating heme oxygenase-1. Circulation (2004) 110(13):1855-60. doi:10.1161/01.CIR.0000142610.10530.25

51. Yamada N, Yamaya M, Okinaga S, Nakayama K, Sekizawa K, Shibahara S, et al. Microsatellite polymorphism in the heme oxygenase-1 gene promoter is associated with susceptibility to emphysema. Am J Hum Genet (2000) 66(1):187-95. doi:10.1086/302729

52. Taha H, Skrzypek K, Guevara I, Nigisch A, Mustafa S, Grochot-Przeczek A, et al. Role of heme oxygenase-1 in human endothelial cells: lesson from the promoter allelic variants. Arterioscler Thromb Vasc Biol (2010) 30(8):1634-41. doi:10.1161/ ATVBAHA.110.207316

53. Schillinger M, Exner M, Mlekusch W, Domanovits H, Huber K, Mannhalter $\mathrm{C}$, et al. Heme oxygenase-1 gene promoter polymorphism is associated with abdominal aortic aneurysm. Thromb Res (2002) 106(2):131-6. doi:10.1016/ S0049-3848(02)00100-7

54. Morgan L, Hawe E, Palmen J, Montgomery H, Humphries SE, Kitchen N. Polymorphism of the heme oxygenase-1 gene and cerebral aneurysms. $\mathrm{Br} J$ Neurosurg (2005) 19(4):317-21. doi:10.1080/02688690500305456

55. Gregorek AC, Gornik KC, Polancec DS, Dabelic S. GT microsatellite repeats in the heme oxygenase-1 gene promoter associated with abdominal aortic aneurysm in Croatian patients. Biochem Genet (2013) 51(5-6):482-92. doi:10.1007/ s10528-013-9579-8

56. Blatter LA, Taha Z, Mesaros S, Shacklock PS, Wier WG, Malinski T. Simultaneous measurements of $\mathrm{Ca} 2+$ and nitric oxide in bradykinin-stimulated vascular endothelial cells. Circ Res (1995) 76(5):922-4. doi:10.1161/01.RES.76.5.922

57. Malinski T, Taha Z. Nitric oxide release from a single cell measured in situ by a porphyrinic-based microsensor. Nature (1992) 358(6388):676-8. doi:10.1038/358676a0

58. Kanai AJ, Strauss HC, Truskey GA, Crews AL, Grunfeld S, Malinski T. Shear stress induces ATP-independent transient nitric oxide release from vascular endothelial cells, measured directly with a porphyrinic microsensor. Circ Res (1995) 77(2):284-93. doi:10.1161/01.RES.77.2.284

59. Huk I, Nanobashvili J, Neumayer C, Punz A, Mueller M, Afkhampour K, et al. 1-arginine treatment alters the kinetics of nitric oxide and superoxide release 
and reduces ischemia/reperfusion injury in skeletal muscle. Circulation (1997) 96(2):667-75. doi:10.1161/01.CIR.96.2.667

60. Cosentino F, Patton S, d'Uscio LV, Werner ER, Werner-Felmayer G, Moreau $\mathrm{P}$, et al. Tetrahydrobiopterin alters superoxide and nitric oxide release in prehypertensive rats. J Clin Invest (1998) 101(7):1530-7. doi:10.1172/JCI650

61. Huk I, Brovkovych V, Nanobash Vili J, Weigel G, Neumayer C, Partyka L, et al. Bioflavonoid quercetin scavenges superoxide and increases nitric oxide concentration in ischaemia-reperfusion injury: an experimental study. Br J Surg (1998) 85(8):1080-5. doi:10.1046/j.1365-2168.1998.00787.x

62. Mason RP, Jacob RF, Corbalan JJ, Szczesny D, Matysiak K, Malinski T. The favorable kinetics and balance of nebivolol-stimulated nitric oxide and peroxynitrite release in human endothelial cells. BMC Pharmacol Toxicol (2013) 14:48. doi: 10.1186/2050-6511-14-48

63. Mason RP, Jacob RF, Kubant R, Jacoby A, Louka F, Corbalan JJ, et al. Effects of angiotensin receptor blockers on endothelial nitric oxide release: the role of eNOS variants. Br J Clin Pharmacol (2012) 74(1):141-6. doi:10.1111/j.1365-2125.2012.04189.x

64. Gao L, Siu KL, Chalupsky K, Nguyen A, Chen P, Weintraub NL, et al. Role of uncoupled endothelial nitric oxide synthase in abdominal aortic aneurysm formation: treatment with folic acid. Hypertension (2012) 59(1):158-66. doi:10.1161/ HYPERTENSIONAHA.111.181644

65. Johanning JM, Armstrong PJ, Franklin DP, Han DC, Carey DJ, Elmore JR. Nitric oxide in experimental aneurysm formation: early events and consequences of nitric oxide inhibition. Ann Vasc Surg (2002) 16(1):65-72. doi:10.1007/ s10016-001-0139-z

66. Kuhlencordt PJ, Gyurko R, Han F, Scherrer-Crosbie M, Aretz TH, Hajjar R, et al. Accelerated atherosclerosis, aortic aneurysm formation, and ischemic heart disease in apolipoprotein E/endothelial nitric oxide synthase double-knockout mice. Circulation (2001) 104(4):448-54. doi:10.1161/hc2901.091399

67. Lee JK, Borhani M, Ennis TL, Upchurch GR Jr, Thompson RW. Experimental abdominal aortic aneurysms in mice lacking expression of inducible nitric oxide synthase. Arterioscler Thromb Vasc Biol (2001) 21(9):1393-401. doi:10.1161/ hq0901.095750

68. Lizarbe TR, Tarin C, Gomez M, Lavin B, Aracil E, Orte LM, et al. Nitric oxide induces the progression of abdominal aortic aneurysms through the matrix metalloproteinase inducer EMMPRIN. Am J Pathol (2009) 175(4):1421-30. doi:10.2353/ajpath.2009.080845

69. Zeinali-Davarani S, Sheidaei A, Baek S. A finite element model of stress-mediated vascular adaptation: application to abdominal aortic aneurysms. Comput Methods Biomech Biomed Engin (2011) 14(9):803-17. doi:10.1080/10255842.2 010.495344

70. Wu S, Jacoby AM, Jasinski K, Kubant R, Malinski T. Ultraviolet B light-induced nitric oxide/peroxynitrite imbalance in keratinocytes - implications for apoptosis and necrosis. Photochem Photobiol (2010) 86:389-96. doi:10.111 1/j.1751-1097.2009.00682.x20074088

71. Kalinowski L, Malinski T. Endothelial NADH/NADPH-dependent enzymatic sources of superoxide production: relationship to endothelial dysfunction. Acta Biochim Pol (2004) 51(2):459-69.

72. Jozkowicz A, Dulak J, Nigisch A, Funovics P, Weigel G, Polterauer P, et al. Involvement of nitric oxide in angiogenic activities of vascular endothelial growth factor isoforms. Growth Factors (2004) 22(1):19-28. doi:10.1080/0897719041682863

73. Eiserich JP, Baldus S, Brennan ML, Ma W, Zhang C, Tousson A, et al. Myeloperoxidase, a leukocyte-derived vascular NO oxidase. Science (2002) 296(5577):2391-4. doi:10.1126/science.1106830

74. Ramos-Mozo P, Madrigal-Matute J, Martinez-Pinna R, Blanco-Colio LM, Lopez JA, Camafeita E, et al. Proteomic analysis of polymorphonuclear neutrophils identifies catalase as a novel biomarker of abdominal aortic aneurysm: potential implication of oxidative stress in abdominal aortic aneurysm progression. Arterioscler Thromb Vasc Biol (2011) 31(12):3011-9. doi:10.1161/ atvbaha.111.237537

75. Michel JB, Martin-Ventura JL, Egido J, Sakalihasan N, Treska V, Lindholt J, et al. Novel aspects of the pathogenesis of aneurysms of the abdominal aorta in humans. Cardiovasc Res (2011) 90(1):18-27. doi:10.1093/cvr/cvq337

76. Eliason JL, Hannawa KK, Ailawadi G, Sinha I, Ford JW, Deogracias MP, et al. Neutrophil depletion inhibits experimental abdominal aortic aneurysm formation. Circulation (2005) 112(2):232-40. doi:10.1161/CIRCULATIONAHA.104.517391
77. Middleton RK, Lloyd GM, Bown MJ, Cooper NJ, London NJ, Sayers RD. The pro-inflammatory and chemotactic cytokine microenvironment of the abdominal aortic aneurysm wall: a protein array study. J Vasc Surg (2007) 45(3):574-80. doi:10.1016/j.jvs.2006.11.020

78. Houard X, Ollivier V, Louedec L, Michel JB, Back M. Differential inflammatory activity across human abdominal aortic aneurysms reveals neutrophil-derived leukotriene B4 as a major chemotactic factor released from the intraluminal thrombus. FASEB J (2009) 23(5):1376-83. doi:10.1096/fj.08-116202

79. Pagano MB, Zhou HF, Ennis TL, Wu X, Lambris JD, Atkinson JP, et al. Complement-dependent neutrophil recruitment is critical for the development of elastase-induced abdominal aortic aneurysm. Circulation (2009) 119(13):1805-13. doi:10.1161/CIRCULATIONAHA.108.832972

80. Thurman JM, Lenderink AM, Royer PA, Coleman KE, Zhou J, Lambris JD, et al. C3a is required for the production of CXC chemokines by tubular epithelial cells after renal ischaemia/reperfusion. J Immunol (2007) 178(3):1819-28. doi:10.4049/jimmunol.178.3.1819

81. Kuijper PH, Gallardo Torres HI, Lammers JW, Sixma JJ, Koenderman L, Zwaginga JJ. Platelet and fibrin deposition at the damaged vessel wall: cooperative substrates for neutrophil adhesion under flow conditions. Blood (1997) 89(1):166-75.

82. Ward C, Chilvers ER, Lawson MF, Pryde JG, Fujihara S, Farrow SN, et al. NF-kappaB activation is a critical regulator of human granulocyte apoptosis in vitro. J Biol Chem (1999) 274(7):4309-18. doi:10.1074/jbc.274.7.4309

83. Sakalihasan N, Delvenne P, Nusgens BV, Limet R, Lapiere CM. Activated forms of MMP2 and MMP9 in abdominal aortic aneurysms. J Vasc Surg (1996) 24(1):127-33. doi:10.1016/S0741-5214(96)70153-2

84. Folkesson M, Kazi M, Zhu C, Silveira A, Hemdahl AL, Hamsten A, et al. Presence of NGAL/MMP-9 complexes in human abdominal aortic aneurysms. Thromb Haemost (2007) 98(2):427-33.

85. Abdul-Hussien H, Soekhoe RG, Weber E, von der Thusen JH, Kleemann R, Mulder A, et al. Collagen degradation in the abdominal aneurysm: a conspiracy of matrix metalloproteinase and cysteine collagenases. Am J Pathol (2007) 170(3):809-17. doi:10.2353/ajpath.2007.060522

86. Pagano MB, Bartoli MA, Ennis TL, Mao D, Simmons PM, Thompson RW, et al. Critical role of dipeptidyl peptidase I in neutrophil recruitment during the development of experimental abdominal aortic aneurysms. Proc Natl Acad Sci U S A (2007) 104(8):2855-60. doi:10.1073/pnas.0606091104

87. Adkison AM, Raptis SZ, Kelley DG, Pham CT. Dipeptidyl peptidase I activates neutrophil-derived serine proteases and regulates the development of acute experimental arthritis. J Clin Invest (2002) 109(3):363-71. doi:10.1172/jci13462

88. Defawe OD, Colige A, Lambert CA, Delvenne P, Lapiere Ch. M, Limet R, et al. Gradient of proteolytic enzymes, their inhibitors and matrix proteins expression in a ruptured abdominal aortic aneurysm. Eur J Clin Invest (2004) 34(7):513-4. doi:10.1111/j.1365-2362.2004.01371.x

89. Choke E, Cockerill GW, Dawson J, Wilson RW, Jones A, Loftus IM, et al. Increased angiogenesis at the site of abdominal aortic aneurysm rupture. Ann N Y Acad Sci (2006) 1085:315-9. doi:10.1196/annals.1383.007

90. Lindholt JS. Aneurysmal wall calcification predicts natural history of small abdominal aortic aneurysms. Atherosclerosis (2008) 197(2):673-8. doi:10.1016/j. atherosclerosis.2007.03.012

91. Ramos-Mozo P, Madrigal-Matute J, Vega de Ceniga M, Blanco-Colio LM, Meilhac $\mathrm{O}$, Feldman L, et al. Increased plasma levels of NGAL, a marker of neutrophil activation, in patients with abdominal aortic aneurysm. Atherosclerosis (2012) 220(2):552-6. doi:10.1016/j.atherosclerosis.2011.11.023

92. Affirul CA, Azim IM, Hanafiah H, Nor Azmi K, Rozman Z. MMP-9: biomarker for abdominal aneurysm. Clin Ter (2013) 164(6):e479-83. doi:10.7417/ct.2013.1640

93. Curci JA, Petrinec D, Liao S, Golub LM, Thompson RW. Pharmacologic suppression of experimental abdominal aortic aneurysms: a comparison of doxycycline and four chemically modified tetracyclines. J Vasc Surg (1998) 28(6):1082-93. doi:10.1016/S0741-5214(98)70035-7

94. Abdul-Hussien H, Hanemaaijer R, Verheijen JH, van Bockel JH, Geelkerken RH, Lindeman JH. Doxycycline therapy for abdominal aneurysm: improved proteolytic balance through reduced neutrophil content. J Vasc Surg (2009) 49(3):741-9. doi:10.1016/j.jvs.2008.09.055

95. Curci JA, Mao D, Bohner DG, Allen BT, Rubin BG, Reilly JM, et al. Preoperative treatment with doxycycline reduces aortic wall expression and activation of matrix metalloproteinases in patients with abdominal aortic aneurysms. $J$ Vasc Surg (2000) 31(2):325-42. doi:10.1016/S0741-5214(00)90163-0 
96. Lindeman JH, Abdul-Hussien H, van Bockel JH, Wolterbeek R, Kleemann R. Clinical trial of doxycycline for matrix metalloproteinase- 9 inhibition in patients with an abdominal aneurysm: doxycycline selectively depletes aortic wall neutrophils and cytotoxic T cells. Circulation (2009) 119(16):2209-16. doi:10.1161/CIRCULATIONAHA.108.806505

97. Thompson SG, Brown LC, Sweeting MJ, Bown MJ, Kim LG, Glover MJ, et al. Systematic review and meta-analysis of the growth and rupture rates of small abdominal aortic aneurysms: implications for surveillance intervals and their cost-effectiveness. Health Technol Assess (2013) 17(41):1-118. doi:10.3310/ hta 17410

98. Khosla S, Morris DR, Moxon JV, Walker PJ, Gasser TC, Golledge J. Meta-analysis of peak wall stress in ruptured, symptomatic and intact abdominal aortic aneurysms. BrJSurg (2014) 101(11):1350-7; discussion 7. doi:10.1002/bjs.9578

99. Rubano E, Mehta N, Caputo W, Paladino L, Sinert R. Systematic review: emergency department bedside ultrasonography for diagnosing suspected abdominal aortic aneurysm. Acad Emerg Med (2013) 20(2):128-38. doi:10.1111/acem.12080

100. Qin C, Chen L, Xiao YB. Emergent endovascular vs. open surgery repair for ruptured abdominal aortic aneurysms: a meta-analysis. PLoS One (2014) 9(1):e87465. doi:10.1371/journal.pone.0087465

101. Volodos NL. Historical perspective: the first steps in endovascular aortic repair: how it all began. J Endovasc Ther (2013) 20(Suppl 1):I3-23. doi:10.1583/15451550-20.sp1.I-3

102. Thompson RW, Adams DH, Cohen JR, Mannick JA, Whittemore AD. Disseminated intravascular coagulation caused by abdominal aortic aneurysm. J Vasc Surg (1986) 4(2):184-6. doi:10.1016/0741-5214(86)90421-0

103. de Maistre E, Terriat B, Lesne-Padieu AS, Abello N, Bouchot O, Steinmetz EF. High incidence of venous thrombosis after surgery for abdominal aortic aneurysm. J Vasc Surg (2009) 49(3):596-601. doi:10.1016/j.jvs.2008.10.005

104. Adam DJ, Haggart PC, Ludlam CA, Bradbury AW. Coagulopathy and hyperfibrinolysis in ruptured abdominal aortic aneurysm repair. Ann Vasc Surg (2004) 18(5):572-7. doi:10.1007/s10016-004-0087-5

105. Holmberg A, Siegbahn A, Westman B, Bergqvist D. Ischaemia and reperfusion during open abdominal aortic aneurysm surgery induce extensive thrombin generation and activity. Eur J Vasc Endovasc Surg (1999) 18(1):11-6. doi:10.1053/ ejvs.1999.0844

106. Trellopoulos G, Georgiadis GS, Nikolopoulos ES, Kapoulas KC, Georgakarakos EI, Lazarides MK. Antiplatelet treatment and prothrombotic diathesis following endovascular abdominal aortic aneurysm repair. Angiology (2014) 65(9):783-7. doi:10.1177/0003319713505139

107. Abdelhamid MF, Davies RS, Vohra RK, Adam DJ, Bradbury AW. Effect of endovascular and open abdominal aortic aneurysm repair on thrombin generation and fibrinolysis. J Vasc Surg (2013) 57(1):103-7. doi:10.1016/j.jvs.2012.07.024

108. Bailey MA, Griffin KJ, Sohrabi S, Whalley DJ, Johnson AB, Baxter PD, et al. Plasma thrombin-antithrombin complex, prothrombin fragments 1 and 2, and D-dimer levels are elevated after endovascular but not open repair of infrarenal abdominal aortic aneurysm. J Vasc Surg (2013) 57(6):1512-8. doi:10.1016/j. jvs.2012.12.030

109. Paravastu SC, Jayarajasingam R, Cottam R, Palfreyman SJ, Michaels JA, Thomas SM. Endovascular repair of abdominal aortic aneurysm. Cochrane Database Syst Rev (2014) 1:Cd004178. doi:10.1002/14651858.CD004178.pub2

110. Qadura M, Pervaiz F, Harlock JA, Al-Azzoni A, Farrokhyar F, Kahnamoui K, et al. Mortality and reintervention following elective abdominal aortic aneurysm repair. J Vasc Surg (2013) 57(6):1676-83. doi:10.1016/j.jvs.2013.02.013

111. Thomas DM, Hulten EA, Ellis ST, Anderson DM, Anderson N, McRae F, et al. Open versus endovascular repair of abdominal aortic aneurysm in the elective and emergent setting in a pooled population of 37,781 patients: a systematic review and meta-analysis. ISRN Cardiol (2014) 2014:149243. doi:10.1155/2014/149243

112. Lee K, Tang E, Dubois L, Power AH, DeRose G, Forbes TL. Durability and survival are similar after elective endovascular and open repair of abdominal aortic aneurysms in younger patients. J Vasc Surg (2015) 61(3):636-41. doi:10.1016/j. jvs.2014.10.012

113. Twine CP, Boyle JR. Response to 're. Benefits of remote ischemic preconditioning in vascular surgery'. Eur J Vasc Endovasc Surg (2014) 48(6):713. doi:10.1016/j. ejvs.2014.08.028

114. Vinten-Johansen J, Shi W. The science and clinical translation of remote postconditioning. JCardiovasc Med (Hagerstown) (2013) 14(3):206-13. doi:10.2459/ JCM.0b013e32835cecc6
115. Nanobashvili J, Neumayer C, Fuegl A, Punz A, Blumer R, Mittlbock M, et al. Combined L-arginine and antioxidative vitamin treatment mollifies ischemia-reperfusion injury of skeletal muscle. J Vasc Surg (2004) 39(4):868-77. doi:10.1016/j.jvs.2003.10.060

116. Neumayer C, Fugl A, Nanobashvili J, Blumer R, Punz A, Gruber H, et al. Combined enzymatic and antioxidative treatment reduces ischemia-reperfusion injury in rabbit skeletal muscle. J Surg Res (2006) 133(2):150-8. doi:10.1016/j. jss.2005.12.005

117. Eefting D, Ultee KH, Von Meijenfeldt GC, Hoeks SE, ten Raa S, Hendriks JM, et al. Ruptured AAA: state of the art management. J Cardiovasc Surg (Torino) (2013) 54(1 Suppl 1):47-53.

118. Wibmer A, Schoder M, Wolff KS, Prusa AM, Sahal M, Lammer J, et al. Improved survival after abdominal aortic aneurysm rupture by offering both open and endovascular repair. Arch Surg (2008) 143(6):544-9; discussion 50. doi:10.1001/ archsurg.143.6.544

119. Badger S, Bedenis R, Blair PH, Ellis P, Kee F, Harkin DW. Endovascular treatment for ruptured abdominal aortic aneurysm. Cochrane Database Syst Rev (2014) 7:Cd005261. doi:10.1002/14651858.CD005261.pub3

120. Teufelsbauer H, Prusa AM, Wolff K, Polterauer P, Nanobashvili J, Prager M, et al. Endovascular stent grafting versus open surgical operation in patients with infrarenal aortic aneurysms: a propensity score-adjusted analysis. Circulation (2002) 106(7):782-7. doi:10.1161/01.CIR.0000028603.73287.7D

121. Wolff KS, Prusa AM, Polterauer P, Wibmer A, Schoder M, Lammer J, et al. Endografting increases total volume of AAA repairs but not at the expense of open surgery: experience in more than 1000 patients. J Endovasc Ther (2005) 12(3):274-9. doi:10.1583/04-1397mr.1

122. Weiss N, Rodionov RN, Mahlmann A. Medical management of abdominal aortic aneurysms. Vasa (2014) 43(6):415-21. doi:10.1024/0301-1526/a000388

123. Vainas T, Lubbers T, Stassen FR, Herngreen SB, van Dieijen-Visser MP, Bruggeman CA, et al. Serum C-reactive protein level is associated with abdominal aortic aneurysm size and may be produced by aneurysmal tissue. Circulation (2003) 107(8):1103-5. doi:10.1161/01.CIR.0000059938.95404.92

124. van der Meij E, Koning GG, Vriens PW, Peeters MF, Meijer CA, Kortekaas $\mathrm{KE}$, et al. A clinical evaluation of statin pleiotropy: statins selectively and dose-dependently reduce vascular inflammation. PLoS One (2013) 8(1):e53882. doi:10.1371/journal.pone.0053882

125. Krotz F, Sohn HY, Gloe T, Zahler S, Riexinger T, Schiele TM, et al. NAD(P) $\mathrm{H}$ oxidase-dependent platelet superoxide anion release increases platelet recruitment. Blood (2002) 100(3):917-24. doi:10.1182/blood.V100.3.917

126. Mastoraki ST, Toumpoulis IK, Anagnostopoulos CE, Tiniakos D, Papalois A, Chamogeorgakis TP, et al. Treatment with simvastatin inhibits the formation of abdominal aortic aneurysms in rabbits. Ann Vasc Surg (2012) 26(2):250-8. doi:10.1016/j.avsg.2011.09.003

127. Periard D, Guessous I, Mazzolai L, Haesler E, Monney P, Hayoz D. Reduction of small infrarenal abdominal aortic aneurysm expansion rate by statins. Vasa (2012) 41(1):35-42. doi:10.1024/0301-1526/a000161

128. Schouten O, Boersma E, Hoeks SE, Benner R, van Urk H, van Sambeek MR, et al. Fluvastatin and perioperative events in patients undergoing vascular surgery. N Engl J Med (2009) 361(10):980-9. doi:10.1056/NEJMoa0808207

129. Takagi H, Yamamoto H, Iwata K, Goto S, Umemoto T, Group A. Effects of statin therapy on abdominal aortic aneurysm growth: a meta-analysis and meta-regression of observational comparative studies. Eur J Vasc Endovasc Surg (2012) 44(3):287-92. doi:10.1016/j.ejvs.2012.06.021

130. Galinanes EL, Reynolds S, Dombrovskiy VY, Vogel TR. The impact of preoperative statin therapy on open and endovascular abdominal aortic aneurysm repair outcomes. Vascular (2014). doi:10.1177/1708538114552837

131. Piechota-Polanczyk A, Goraca A, Demyanets S, Mittlboeck M, Domenig C, Neumayer C, et al. Simvastatin decreases free radicals formation in the human abdominal aortic aneurysm wall via NF-kappaB. Eur J Vasc Endovasc Surg (2012) 44(2):133-7. doi:10.1016/j.ejvs.2012.04.020

132. Ridker PM, MacFadyen J, Libby P, Glynn RJ. Relation of baseline high-sensitivity C-reactive protein level to cardiovascular outcomes with rosuvastatin in the justification for use of statins in prevention: an intervention trial evaluating rosuvastatin (JUPITER). Am J Cardiol (2010) 106(2):204-9. doi:10.1016/j. amjcard.2010.03.018

133. Piechota-Polanczyk A, Demyanets S, Nykonenko O, Huk I, Mittlboeck M, Domenig CM, et al. Decreased tissue levels of cyclophilin A, a cyclosporine a target and phospho-ERK1/2 in simvastatin patients with abdominal aortic 
aneurysm. Eur J Vasc Endovasc Surg (2013) 45(6):682-8. doi:10.1016/j. ejvs.2013.02.015

134. Ortego M, Bustos C, Hernandez-Presa MA, Tunon J, Diaz C, Hernandez G, et al. Atorvastatin reduces NF-kappaB activation and chemokine expression in vascular smooth muscle cells and mononuclear cells. Atherosclerosis (1999) 147(2):253-61. doi:10.1016/S0021-9150(99)00193-8

135. Rezaie-Majd A, Maca T, Bucek RA, Valent P, Muller MR, Husslein P, et al. Simvastatin reduces expression of cytokines interleukin-6, interleukin-8, and monocyte chemoattractant protein-1 in circulating monocytes from hypercholesterolemic patients. Arterioscler Thromb Vasc Biol (2002) 22(7):1194-9. doi:10.1161/01.ATV.0000022694.16328.CC

136. Steinmetz EF, Buckley C, Shames ML, Ennis TL, Vanvickle-Chavez SJ, Mao D, et al. Treatment with simvastatin suppresses the development of experimental abdominal aortic aneurysms in normal and hypercholesterolemic mice. Ann Surg (2005) 241(1):92-101.

137. Evans J, Powell JT, Schwalbe E, Loftus IM, Thompson MM. Simvastatin attenuates the activity of matrix metalloprotease-9 in aneurysmal aortic tissue. Eur J Vasc Endovasc Surg (2007) 34(3):302-3. doi:10.1016/j.ejvs.2007.04.011

138. Antithrombotic Trialists C, Baigent C, Blackwell L, Collins R, Emberson J, Godwin J, et al. Aspirin in the primary and secondary prevention of vascular disease: collaborative meta-analysis of individual participant data from randomised trials. Lancet (2009) 373(9678):1849-60. doi:10.1016/ S0140-6736(09)60503-1

139. Eldrup N, Budtz-Lilly J, Laustsen J, Bibby BM, Paaske WP. Long-term incidence of myocardial infarct, stroke, and mortality in patients operated on for abdominal aortic aneurysms. J Vasc Surg (2012) 55(2):311-7. doi:10.1016/j. jvs.2011.08.046

140. Chen CY, Huang JW, Tzu-Chi Lee C, Lai WT, Huang YB. Long-term outcome of patients with aortic aneurysms taking low-dose aspirin: a population-based cohort study. J Investig Med (2013) 61(6):1004-12. doi:10.231/ JIM.0b013e318297d0f9

141. Kaber G, Kaiser B, Baumgartel-Allekotte D, Rauch B, Nossmann S, Heim K, et al. Antagonism of the antithrombotic and anti-atherosclerotic actions of aspirin by rofecoxib in the cholesterol-fed rabbit. Br J Pharmacol (2011) 164(2b):561-9. doi:10.1111/j.1476-5381.2011.01392.x

142. Prasad K, Lee P. Suppression of oxidative stress as a mechanism of reduction of hypercholesterolemic atherosclerosis by aspirin. J Cardiovasc Pharmacol Ther (2003) 8(1):61-9. doi:10.1177/107424840300800i109
143. Tauseef M, Shahid M, Sharma KK, Fahim M. Antioxidative action of aspirin on endothelial function in hypercholesterolaemic rats. Basic Clin Pharmacol Toxicol (2008) 103(4):314-21. doi:10.1111/j.1742-7843.2008.00277.x

144. Daugherty A, Cassis L. Angiotensin II and abdominal aortic aneurysms. Curr Hypertens Rep (2004) 6(6):442-6. doi:10.1007/s11906-004-0038-0

145. Tsunemi K, Takai S, Nishimoto M, Yuda A, Hasegawa S, Sawada Y, et al. Possible roles of angiotensin II-forming enzymes, angiotensin converting enzyme and chymase-like enzyme, in the human aneurysmal aorta. Hypertens Res (2002) 25(6):817-22. doi:10.1291/hypres.25.817

146. Liao S, Miralles M, Kelley BJ, Curci JA, Borhani M, Thompson RW. Suppression of experimental abdominal aortic aneurysms in the rat by treatment with angiotensin-converting enzyme inhibitors. J Vasc Surg (2001) 33(5):1057-64. doi:10.1067/mva.2001.112810

147. Hackam DG, Thiruchelvam D, Redelmeier DA. Angiotensin-converting enzyme inhibitors and aortic rupture: a population-based case-control study. Lancet (2006) 368(9536):659-65. doi:10.1016/S0140-6736(06)69250-7

148. Wilmink AB, Vardulaki KA, Hubbard CS, Day NE, Ashton HA, Scott AP, et al. Are antihypertensive drugs associated with abdominal aortic aneurysms? J Vasc Surg (2002) 36(4):751-7. doi:10.1067/mva.2002.126550

149. Sweeting MJ, Thompson SG, Brown LC, Greenhalgh RM, Powell JT. Use of angiotensin converting enzyme inhibitors is associated with increased growth rate of abdominal aortic aneurysms. J Vasc Surg (2010) 52(1):1-4. doi:10.1016/j. jvs.2010.02.264

150. Kortekaas KE, Meijer CA, Hinnen JW, Dalman RL, Xu B, Hamming JF, et al. ACE inhibitors potently reduce vascular inflammation, results of an open proof-of-concept study in the abdominal aortic aneurysm. PLoS One (2014) 9(12):e111952. doi:10.1371/journal.pone.0111952

Conflict of Interest Statement: The authors declare that the research was conducted in the absence of any commercial or financial relationships that could be construed as a potential conflict of interest.

Copyright $\odot 2015$ Piechota-Polanczyk, Jozkowicz, Nowak, Eilenberg, Neumayer, Malinski, Huk and Brostjan. This is an open-access article distributed under the terms of the Creative Commons Attribution License (CC BY). The use, distribution or reproduction in other forums is permitted, provided the original author(s) or licensor are credited and that the original publication in this journal is cited, in accordance with accepted academic practice. No use, distribution or reproduction is permitted which does not comply with these terms. 